Leonardo Becchetti(1), Riccardo Massari(2) and Paolo Naticchioni(3)

(1) University of Rome Tor Vergata

(2) University of Rome La Sapienza

(3) University of Cassino, Sapienza Univ. of Rome, CeLEG-LUISS

The drivers of happiness inequality Suggestions for promoting social cohesion

October 2011 
Dipartimento di Scienze Economiche

Università degli Studi di Cassino

Via S.Angelo Località Folcara, Cassino (FR)

Tel.+3907762994734 Email dipse@eco.unicas.it 


\title{
The drivers of happiness inequality Suggestions for promoting social cohesion
}

\author{
Leonardo Becchetti \\ University of Rome Tor Vergata \\ Riccardo Massari \\ University of Rome La Sapienza \\ Paolo Naticchioni ${ }^{*}$ \\ University of Cassino, Sapienza Univ. of Rome, CeLEG-LUISS
}

October 2011

\begin{abstract}
The goal of this paper is to identify and quantify the contribution of a set of covariates in affecting levels and over time changes of happiness inequality. We make use of a recent methodology that allows decomposing the overall change in happiness inequality into composition and coefficient effects of each covariate. We focus on the increase in happiness inequality observed in Germany between 1991 and 2007 in the German SocioEconomic Panel (GSOEP) database, deriving the following findings. First, trends in happiness inequality are mainly driven by composition effects, while coefficient effects are negligible. Second, among composition effects, education has an inequality-reducing impact, while changes in labour market conditions and demographic composition contribute to explain the rise in happiness inequality. Third, the increase in income inequality cannot be considered as a driver of the increase in happiness inequality. A clear cut policy implication of our paper is that policies enhancing education and labour market performance are crucial to reduce happiness inequality and the potential social tensions arising from it.
\end{abstract}

Keywords: happiness inequality, income inequality, education, decomposition methods. JEL Codes: I31, I28, J17, J21, J28.

Corresponding author. University of Cassino, Via S. Angelo - Località Folcara, 03043 Cassino (FR), Italy, email address: p.naticchioni@gmail.com. 
Economists in the last decades have widely investigated life satisfaction levels and their drivers. ${ }^{1}$ The motivation for our paper is to extend the analysis from life satisfaction levels to life satisfaction inequality. As well-known, unlike income happiness is not transferable. ${ }^{2}$ While policy makers can evaluate whether to redistribute income across individuals, it is not possible to transfer happiness across individuals. Probably for this reason, the literature concerning happiness inequality at the individual level is lacking, with only few recent exceptions such as Stevenson and Wolfers (2008), Van Praag (2011), Dutta and Foster (2011), and Guven et al. (2009). A wider macroeconomic literature is instead available, using cross-country data (ChinHon-Foei, 1989; Veenhoven, 1990 and 2005; Ott, 2010).

The original contribution of our paper consists in identifying at the micro level the individual determinants of both levels and over time changes of happiness inequality. We make use of a decomposition methodology introduced by Firpo et al. (2007) and further developed in Fortin et al. (2011). By using Recentered Influence Function (RIF) regressions (Firpo et al. 2009), this methodology represents a generalization of the Oaxaca-Blinder procedure (Blinder, 1973; Oaxaca, 1973), since it can be applied to any distributional parameter other than the mean. The methodology allows splitting the total change in happiness inequality into two aggregate effects, the first related to the overall changes in the distribution of happiness determinants in the population (composition effect), the second related to the overall changes in the return of such determinants (coefficient, or structure, effect). Once the aggregate decomposition has been carried out, it is also possible to compute a more detailed decomposition, subdividing both the composition and coefficient effects into the contribution of each covariate. ${ }^{3}$

\footnotetext{
We are grateful to Elena Giachin for her suggestions and support in the construction of the database. We thanks Nicole Fortin for her clarifications about the methodology, Joseph Deutsch, Francisco Ferreira, Jacques Silber, Alois Stutzer, Ruut Veenhoven, Bernard Van Praag and Rainer. Winkelmann for their suggestions, as well as the participants to the IZA workshop on redistribution and well-being (Lausanne, 2011), the ECINEQ conference (Catania, 2011), the AIEL conference (Pescara, 2010), the "Health. Happiness. Inequality" workshop (Darmstadt, 2010). Usual disclaimer applies.

${ }^{1}$ The investigation of the determinants of happiness has been one of the most salient topics of economists since the Classics, for instance Malthus (1798). In the history of economic thought the relevance of the investigation on the wealth-happiness nexus was also recognised, among others, by Marshall (1890), Veblen (1899) and, more recently, Dusenberry (1949), Scitovsky (1976) and Hirsch (1976). The topic at that time could be tackled only on philosophical grounds whereas, since a few decades, the wide availability of databases including measures of self declared life satisfaction has provided abundant empirical evidence for testing hypotheses stemming from the happiness debate. ${ }^{2}$ In this paper we use the terms "happiness", "well-being" and "life satisfaction" as synonyms, as usual in the literature.

${ }^{3}$ The approach has been already used to account for changes in wage inequality in several empirical contributions (Firpo et al., 2007, 2011; Chi and Li, 2008; Schirle, 2009).
} 
Identifying and quantifying the contribution of each driver on levels and over time changes of happiness inequality matters from a policy point of view, since it allows policy makers to work on the reduction of social tension (Tullock, 1971, Brown 1996, Gurr 1996), through policies aimed at affecting drivers of happiness inequality. Further, this methodology allows disentangling the impact of those determinants that can be directly redistributed by the policy maker, like income and wealth, from the impact of determinants that cannot be directly redistributed, such as education and employment status. ${ }^{4}$

The measurement and the analysis of happiness is becoming more and more important in the political arena as well. For instance, the UK government plans to evaluate happiness of people with wellbeing indicators to be announced in Autumn 2011, consistently with the statements of the Prime Minister Cameron who argues that "his goal in politics is to help make a better life for people" and "noted that government should be properly focused on quality of life as well as economic growth". ${ }^{5}$ From a more scientific standpoint, a similar argument is proposed by Stiglitz, Sen and Fitoussi (2009) in their report on the measurement of economic performance and social progress. This report underlines the importance of using indicators of self-assessed life satisfaction: "These measures, while not replacing conventional economic indicators, provide an opportunity to enrich policy discussions and to inform people's view of the conditions of the communities where they live. More importantly, the new measures now have the potential to move from research to standard statistical practice" (p.41).

The focus of the paper is on the German case, using the German Socio-Economic Panel (GSOEP). The analysis is composed by two main steps. In the first step we investigate for the two time periods (1991-2-3 and 2005-6-7) the determinants of cross sectional happiness inequality, in terms of variance and Gini index, by means of RIF regressions. In the second, we identify and quantify the role played by each single covariate in shaping the evolution over time of happiness inequality, in terms of the variance and Gini index.

The first step of the analysis shows that education, income, being employed, having a saving account, being a house owner and being married are negatively correlated to happiness inequality, while being unemployed, living in the East and being a prime age individual are positively correlated to happiness inequality. Further, being female and having children do not affect happiness inequality

\footnotetext{
${ }^{4}$ Van Praag (2011) comments that ".. most of [the] determinants [of well-being] cannot be redistributed but they are relevant for well-being, and inter-individual differences in those nonincome determinants may cause feelings of well-being inequality as well".

${ }^{5}$ See http://algarvedailynews.com/news/4007-uk-happiness-assessment-in-hand accessed on July $27,2011$.
} 
As for the second step of the analysis, the decomposition procedure, we derive the following findings. First, most of the dynamics of happiness inequality is explained by the composition effect, while the coefficient effect is negligible, suggesting that the returns to drivers are invariant over time. Second, the increase in education level has a reducing effect on happiness inequality. Third, changes in labour market conditions (mainly being unemployed) strongly contribute to the increase in happiness inequality. Additional roles are played by a demographic effect, since the increase in the middle age cohort share of the population is associated with an increase in happiness inequality, and by the decline in the share of individuals with a saving account, suggesting that reduction of financial well-being contributes as well to the observed increase in inequality. Finally, the increase in income inequality in Germany cannot be considered as a driver of the increase in happiness inequality, confirming the findings of Stevenson and Wolfers (2008), i.e. the increasing income inequality in the US has not translated into higher happiness inequality.

Since happiness inequality is a driver of social tensions, we conclude by suggesting that education and labour market policies, apart from the well known effects emphasized in the macroeconomic and labour literature, entail an additional impact on happiness inequality, reducing social unrest.

It is important to stress that we are not claiming that the analysis of happiness inequality has to replace other dimensions of inequality that are currently used by policy makers when deciding redistributive measures (income, wages and so on). Consistently with the report of Stiglitz, Sen and Fitoussi (2009), we simply argue that happiness inequality can represent an additional dimension that policy makers might, and probably should, take into account.

The paper is divided into six sections. In section 2 we discuss the related literature, while in section 3 we illustrate our sample and provide descriptive findings. In section 4 we outline analytical features of the decomposition approach. In section 5 we present econometric findings. In section 6 we discuss further the findings of the paper. The seventh section concludes.

\section{Related literature}

Happiness inequality has mainly been addressed from a macroeconomic standpoint, using cross-country data. Chin-Hon-Foei (1989), analyzing the trends of GDP and happiness inequality for European countries in the period 1975-84, documents a positive correlation between economic fluctuations and happiness inequality. Considering a larger sample of nations, Veenhoven (1990) observes that happiness is 
more equally distributed in more economically stable and developed countries, a finding further confirmed in Veenhoven (2005). Ott (2010) points out that that "good government" increases happiness level and reduces happiness inequality.

Conversely, the micro analysis of happiness inequality is relatively poor from both a theoretical and empirical point of view. Using individual data, Stevenson and Wolfers (2008) document that happiness inequality has substantially decreased in the US from 1970 to 2006. However, since the early 1990s, there is an upward trend, which however does not compensate the massive decrease occurred in the previous decades. Stevenson and Wolfers (2008) explain the falling trend in happiness inequality in terms of a strong erosion of the race and gender happiness gaps. They also show that trends in income inequality and happiness inequality are rather different.

Dutta and Foster (2011) instead focus on the measurement of happiness inequality in the US, adopting the approach of Allison and Foster (2004) for ordinal variables. They find similar patterns as in Stevenson and Wolfers (2008): from 1970's to 1990's happiness inequality decreased, while in the 2000's it has started to rise.

From a theoretical point of view, Van Praag (2011) argues that the reference effect, i.e. the fact that individuals evaluate their conditions taking into account those of their peers, has to be taken into account in order to define properly the concept of wellbeing inequality.

From a different perspective, Guven et al. (2009) provide evidence of a direct link between happiness divide and disruption of relational ties. The authors document that the husband-wife happiness gap has positive impact on the likelihood of separation, thereby assessing a specific case where happiness inequality reduces cohesion in a "small society" such as the household. Finally, Ferrer-i-Carbonell and Van Praag (2006) analyze income satisfaction inequality, which is a related but different concept.

So far the review of the literature concerning happiness inequality. However, two additional streams of the literature are related to our paper, concerning the relation between income inequality and happiness, and between happiness inequality and social cohesion, respectively.

As for the former, Alesina et al. (2004) analyze the effect of income inequality on individual well-being, pointing out different attitudes between the US and Europe. In particular, poor in the US seem to be less concerned about income inequality than in Europe. Graham and Felton (2006) further investigate this topic in Latin America. Two bottom lines emerge from this literature: i) the more income inequality is perceived as a signal of an unfair society, the more happiness is negatively affected by income inequality; ii) the higher the perception of vertical mobility, the lower the sense of unfairness generated by inequality. 
Shifting the focus from levels to inequality of happiness, it is interesting to note that a unified theoretical approach that investigates the relation between income inequality and happiness inequality at the micro level is still lacking. On the one hand, in a simplified utilitarian approach where life satisfaction depends only on personal or household income, an increase in income inequality would generate - under standard microeconomic assumptions - an increase in happiness inequality. In a richer setting, one might claim that the gap from the income of the reference group might generate positive effects on happiness inequality also because of envy issues (Van Praag, 2011). Furthermore, in a framework where jobs characterized by high incomes are also associated to higher work satisfaction and greater capability in evaluating the working time as enjoying and stimulating, an increase in income inequality might generate a more than proportional impact on happiness inequality, since all these non pecuniary factors are supposed to enlarge differences between the wealthy and poor (Scitovsky, 1974).

On the other hand, income inequality may be paradoxically perceived as even positive by the poor, in such a way reducing happiness inequality, since it can be considered as a signal of what they might achieve in the future. ${ }^{6}$ In these cases expectations of vertical mobility are such that income divide does not translate into happiness divide and economic inequality may be not at odd with social cohesion.

The only available evidence concerning income inequality and happiness inequality are carried out in a macroeconomic framework, by means of cross-country analysis. For instance, Ovaska and Takashima (2010) observe that income inequality positively affects happiness inequality.

As for the relation between happiness inequality and social cohesion, both "discontent theories" and "expected utility theories" of rebellion (or, more mildly, social protest) predict a positive relation between life satisfaction gaps and social unrest. According to "discontent theories", lack of life satisfaction has a strong effect on social upheaval (e.g. Brown, 1996, Gurr, 1996). According to "expected utility theories", the effect is conditional since rational individuals participate in rebellious actions only if the costs are lower than the expected gain (Tullock, 1971). However, expected gains are reasonably proxied by the satisfaction gap between those who are happy and those who are unhappy times the probability of riot success, suggesting that the life satisfaction gap has a crucial effect on social unrest. ${ }^{7}$

\footnotetext{
${ }^{6}$ Jiang et al. (2009) document this point in urban China, while Senik (2004) and Becchetti and Savastano (2010) in transition countries. The standard rationale which may explain this anomaly is the so called tunnel effect hypothesis (Hirschman, 1973). If an individual is stuck in a traffic jam and observes that, after a while, a car in the contiguous lane starts moving he may get happier if interpreting the move as a signal that she is soon also starting to move.

${ }^{7}$ This is clearly set out in the Guimaraes and Sheedy (2010) model of equilibrium institutions where the authors postulate that "the most dissatisfied individuals have the most to gain from a rebellion".
} 
Overall, all this literature suggests that happiness gaps can be considered as a direct cause of envy and social tensions, while income gap is an indirect one. This is because income and/or social divide may not necessarily result into happiness divide due to the compensating effect of many other non pecuniary factors affecting life satisfaction (chances of achievement, quality of leisure and relational life, etc.). Put in other terms, a social group may be much poorer than another group in a society but if it is compensated by other sources of satisfaction, the economic divide will not generate per se social tensions.

\section{Sample and descriptive findings}

The GSOEP is one of the most accurate panel databases containing information on life satisfaction and, as such, it is widely used in empirical papers in this literature. ${ }^{8} \mathrm{We}$ select for our inquiry two time periods, the first one including the years 1991, 1992, and 1993, and the second one the years 2005, 2006, and 2007. This time span is homogeneous from a social and political point of view, being posterior to the German reunification. Excluding the individuals for which at least one variable of the analysis is missing, we end up with 24,838 observations for the first time period and 38,583 for the second period.

The main variable of interest, Life Satisfaction, is measured in the GSOEP database as a 0-10 categorical ordered variable. ${ }^{9}$ In this work we assume this variable as cardinal (see section 5 for a justification of this assumption) and this enables us to evaluate some standard measures of distribution inequality, viz. variance and Gini index.

On average, in Germany happiness decreased over time from 6.955 to 6.790 (-2.5\%), while happiness inequality increased over the period, since the variance increased by $7.8 \%$, from 3.222 to 3.473 and the Gini index increased by around 7\%, from 0.137 to 0.146. ${ }^{10}$ These trends are consistent with those observed in the World Database of Happiness (Veenhoven, 2009), which documents an increase in inequality in Germany. ${ }^{11}$ A similar trend is observed in the US by Stevenson and Wolfers (2008), who detect a fall in happiness inequality from the seventies, with an inversion of such trend from the beginning of the nineties. It is also worth noting that, in accordance

\footnotetext{
${ }^{8}$ See, among others, Frijters et al. (2004a and 2004b).

9 The GSOEP question is "How satisfied are you with your life, all things considered?". The responses are rated from 0 (completely dissatisfied) to 10 (completely satisfied).

${ }^{10}$ Since there is evidence of a significant drop in self reported life satisfaction as an individual is in the panel for a long period (Frijters and Beatton, 2008). However, this should hardly affect our results, since we analyze data in a cross section perspective. As long as this bias is attributable to attrition effects related to time-varying unobservables, cross-section results remain still valid.

${ }^{11}$ In particular, standard deviation of happiness increases from 1.77 in 1993 (source: SOEP), to 2.22 in 2007 (source: European Social Survey, ESS).
} 
with the World Database of Happiness, in most of the developed countries happiness inequality has decreased. In such a framework, the German case represents a peculiar and interesting case to study.

In order to find out which are the driving forces of happiness inequality we focus on those covariates the literature has shown to be important happiness determinants (age, individual income and relative income, education, marital status and having children, employment status, saving status and house ownership). ${ }^{12}$ Table A1, in Appendix, provides definitions of these covariates, while Table 1 reports covariates' mean values in the two considered time periods. ${ }^{13}$

The main trends observed in the GSOEP sample are the following: a) the population is getting older and more educated; b) the shares of widowed, separations, divorces, included in the variable 'no more married' increase, as well as the share of households without children, while the share of marriages decreases; c) income inequality increases, since shares of individuals in the bottom and median quintiles decrease, while shares in top quintiles increase; ${ }^{14} \mathrm{~d}$ ) on average, the share of individuals included in the first quartile of the distribution of relative income increases over time, while those included in the top quartile decreases; e) the employment rate is basically stable (slightly higher in the second period) while the unemployment rate increases, and the share of retired decreases; $f$ ) the share of house owners increases slightly over time, while g) the share of individuals having a saving account gets lower.

Can the rise in happiness inequality be explained by the above mentioned changes in covariates and to what extent? In the following section we outline the methodological approach which allows answering to these questions.

\footnotetext{
${ }^{12}$ All the variables are expressed as dummies. This is far from being restrictive and it is useful to ease the interpretation of the composition effect, in particular. To measure the income variable, we consider the quintiles of the yearly disposable equivalent income deflated using OECD deflator (base year 2007), computed on the pooled sample of the two periods (1991, 1992, 1993, and 2005, 2006 and 2007). Relative income is considered in order to control for the influence of the reference group (Van Praag, 2011). It is derived by computing the quartiles of the relative income distribution (individuals with the same gender, age class, education, Lander) in the pooled version of the data. The variable relatively poor is equal to one when the individual belongs to the first quartile of the distribution, while relatively rich is equal to one when the individual belongs to the top quartile.

${ }^{13}$ For an overview of findings on happiness determinants see, among others, Frey and Stutzer (2002a), Dolan et al. (2008), and Clark et al. (2006), the latter specifically addressing the relationship between happiness and income.

${ }^{14}$ Such changes in income inequality in the nineties are consistent with the documented increase in wage inequality in both East and West Germany (Gernandt and Pfeiffer, 2007, Dustmann et al., 2008).
} 


\section{The decomposition approach and its application to life satisfaction data}

\subsection{Methodological problems}

In this section we briefly summarize the methodological problems concerning the happiness literature, both in general and with respect to inequality issues. Other methodological issues regarding the Gini index as a measure of happiness inequality are instead discussed in section 5 .

In the happiness literature, two main issues deserve to be mentioned. First, there are no a priori reasons to assume that scales used for self reported life satisfaction are homogenous across different individuals, suggesting extreme caution when making interpersonal comparisons (Harsanyi, 1955). ${ }^{15}$ Second, evaluation of happiness inequality requires the assumption of cardinality of self reported life satisfaction.

As for as the first issue is concerned, several authors observe that scale heterogeneity does not prevent the use of life satisfaction data in empirical analysis. Cantril (1965) finds that individual evaluations on the 0-10 scales are quite comparable. Di Tella and McCulloch (2006) argue that, even in presence of heterogeneity in individual scales, there are no a priori reasons to believe that such heterogeneity is systematically affected by drivers of life satisfaction. On the same vein, Frey and Stutzer (2002a) admit the existence of heterogeneity in the scales used for self-reported life satisfactions, but argue that this does not invalidate regression results, since they expect such heterogeneity to be random.

An important step forward in this discussion is the possibility to test empirically whether such heterogeneity alters estimates from standard life satisfaction regressions. In this respect, Beegle et al. (2011) provide a clear example of frame of reference bias, and tests the validity of the Frey and Stutzer (2002a) argument by means of the vignette approach. Individuals are asked to rank the economic status of theoretical vignette households, as well as of their own status. Respondent's own scales are derived from their vignette rankings. The authors' findings confirm the presence of heterogeneity in individual scales, but also reject, with three different tests, the hypothesis that such heterogeneity alters results of the standard life satisfaction regressions. First, heterogeneity is uncorrelated with happiness determinants. Second, vignette rankings are not correlated with the residual of the standard life satisfaction regressions. Third, results on the determinants of life satisfaction do not change when self declared life satisfaction is rescaled with vignette results.

\footnotetext{
${ }^{15}$ An additional problem is when interpersonal comparisons among people from different countries end up being complicated by the presence of different language nuances, given that the word "happiness" has not the same meaning in different languages. Furthermore, cultural habits are also likely to generate additional biases (it may be considered polite and correct in a given culture to declare oneself always satisfied while, in another one, people may tend to overcomplain).
} 
The second methodological issue discussed in the literature concerns the fact that the life satisfaction variable is usually reported in an ordinal scale, while measuring happiness inequality requires a cardinal concept of happiness, since we want to detect not only if an individual is happier than another, but also how much she/he is happier.

The literature pointed out that considering happiness and satisfaction variables as either cardinal or ordinal leads to similar results in a regression framework (Ferrer-ICarbonell and Frijters, 2004; Van Praag and Ferrer-i-Carbonell, 2004, 2006; Van Praag, 2007). ${ }^{16}$ Further, Clark et al. (2009) observe that doctors implicitly reveal to believe in cardinality when asking to their patients how much a given part of the body hurts after a touch (and base on an implicit comparison of other patients' declarations their evaluation of the relevance of the pain). As a matter of fact, doctors and psychologists also use cardinality in the self assessed health (SAH) literature with measures that are precise predictors of future mortality and morbidity (Idler and Benyamini, 1997).

More in general, there is also a long tradition in the literature, especially in the social science, which treats ordinal categorical variables as cardinal and continuous. Several works have shown that the bias introduced by the continuity assumption is rather small when data are characterized by a high number of categories (Bollen and Barb, 1981, 1983; Srinivasan and Amiya, 1989).

Based on this robust literature, and on the general consensus on the use of happiness data in the growing literature on life satisfaction, we treat our dependent variable, self-reported life satisfaction, as cardinal.

\subsection{Decomposition methodology}

In this subsection we illustrate the decomposition methodology applied to happiness inequality.

Let $Y$ be the self reported degree of life satisfaction. Let also $Y_{i 1}$ be the life satisfaction of an individual $i$ observed in period 1, and $Y_{i 0}$ the corresponding value in period 0 . For each individual $i$ the observed degree of life satisfaction is $Y_{i}=Y_{i 1} \cdot T_{i}+Y_{i 0} \cdot\left(1-T_{i}\right)$, where $T_{i}=1$ if individual $i$ is observed in period 1 , and 0 otherwise. Finally, let $X$ be a vector of $K$ individual covariates, which are observed in both periods.

\footnotetext{
${ }^{16}$ Van Praag $(2007$, p. 18) argues that "All these specifications amount to different specifications of the labeling system of the underlying indifference curves, but the indifference curves themselves are unchanged and are these indifference curves which are estimated, either by Ordered Probit, Logit or what else."
} 
The conditional mean of $Y$ on $X$ at time $t=0,1$ can be written as $E(Y \mid X, T=t)=X \beta_{t}$, where $\beta_{t}$ is the vector of regression coefficients, which can be estimated by OLS.

The Oaxaca-Blinder (henceforth OB) decomposition (Blinder, 1973; Oaxaca, 1973) allows to break down the overall difference in means, $\Delta_{O}^{\mu}=\mu_{1}-\mu_{0}$, into two components, one related to the changes in the returns of the set of covariates, the coefficient or structure effect, $\Delta_{S}^{\mu}$, and the other linked to the changes in the distribution of these covariates, the composition effect, $\Delta_{X}^{\mu}$. These two effects can be easily derived by adding and subtracting a counterfactual mean, for instance $E(X \mid T=1) \beta_{0}$, as in the following:

$$
\begin{aligned}
& \Delta_{O}^{\mu}=\mu_{1}-\mu_{0}=E(X \mid T=1) \beta_{1}-E(X \mid T=0) \beta_{0} \pm E(X \mid T=1) \beta_{0}= \\
& =E[X \mid T=1]\left(\beta_{1}-\beta_{0}\right)+(E[X \mid T=1]-E[X \mid T=0]) \beta_{0}=\Delta_{S}^{\mu}+\Delta_{X}^{\mu}
\end{aligned}
$$

thus yielding the "aggregate" decomposition.

By means of the $\mathrm{OB}$ decomposition, it is also possible to identify the contribution of each covariate to these two effects, the "detailed" decomposition. More specifically, the two effects can be written in terms of the explanatory variables in the following way:

$$
\begin{aligned}
& \Delta_{S}^{\mu}=E[X \mid T=1]\left(\beta_{1}-\beta_{0}\right)=\sum_{k=1}^{K} E\left[X_{k} \mid T=1\right] \mid\left(\beta_{1, k}-\beta_{0, k}\right) \\
& \Delta_{X}^{\mu}=(E[X \mid T=1]-E[X \mid T=0]) \beta_{0}=\sum_{k=1}^{K}\left\{E\left[X_{k} \mid T=1\right]-E\left[X_{k} \mid T=0\right]\right\} \beta_{0, k}
\end{aligned}
$$

where $X_{k}$ and $\beta_{t, k}$ are the $k$-th elements of the vector of covariates and of the vector of regression coefficients, respectively.

Fortin et al. (2011) extend the aggregate and the detailed decomposition of the mean provided by Oaxaca-Blinder to any distributional parameter other than the mean, $v$, like median, quantiles, variance or Gini index. The basic idea is to estimate a linear regression where $Y$ is replaced by the recentered influence function (RIF) of the parameter $v, R I F(y ; v)$. The RIF is obtained by adding the distributional parameter of interest to the influence function $I F(y ; v) .{ }^{17}$

\footnotetext{
${ }^{17}$ The influence function (Hampel, 1974) is a statistical tool, used to assess the robustness of a distributional statistic to the presence of outliers, which detects the contribution (also defined as influence) of each observation to the distributional parameter of interest. As an example, the influence function of the variance is $(y-\mu)^{2}-\sigma^{2}$, and the RIF is $\sigma^{2}+\left[(y-\mu)^{2}-\sigma^{2}\right]=(y-\mu)^{2}$.
} 
An useful property of the $R I F(y ; v)$ is that its expected value is the statistic of interest. Hence, using the law of iterated expectations, it is possible to write:

$$
v=E[R I F(Y ; v)]=E_{X}\{E[R I F(Y ; v) \mid X]\}
$$

In its simplest form, the conditional expectation of the $R I F(y ; v)$ can be written as a linear function of the covariates, yielding the RIF regression (Firpo et al, 2009):

$$
E[R I F(Y ; v) \mid X]=X \gamma^{v}
$$

where the parameters $\gamma_{t}^{v}$ can be estimated by OLS.

Similarly to the case of the mean, it is possible to decompose the overall difference over time of $v, \Delta_{O}^{v}=v_{1}-v_{0}=\Delta_{S}^{v}+\Delta_{X}^{v}$, where, analogously to the Oaxaca-Blinder decomposition, the coefficient and composition effects can be written as:

$$
\begin{aligned}
& \Delta_{S}^{v}=E[X \mid T=1]^{\prime}\left(\gamma_{1}^{v}-\gamma_{0}^{v}\right) \\
& \Delta_{X}^{v}=(E[X \mid T=1]-E[X \mid T=0])^{\prime} \gamma_{0}^{v}
\end{aligned}
$$

Note, however, that the above decomposition holds only in the case of a linear specification of the conditional expectation (2). Barsky et al. (2002) show that, in the case of the mean, the OB decomposition is biased.

Fortin et al. (2011) observe that this bias can occur also for other distributional statistics. Hence, they suggest a solution based both on the Di Nardo et al. (1996) reweighing procedure and on the RIF regression. By reweighing the distribution of $X^{\prime}$ 's in period 0 to have the same distribution as in period 1 , it is possible to estimate the counterfactual mean $\bar{X}_{01}$, as well as the counterfactual coefficients $\hat{\gamma}_{01}^{v}$ from the regression of $\operatorname{RIF}\left(Y_{0} ; v\right)$ on the reweighted sample.

Hence, in line with (1), by adding and subtracting the counterfactual estimated RIFregression $\bar{X}_{01} \hat{\gamma}_{01}^{v}$ it is possible to decompose the overall change as:

$$
\Delta_{O}^{v}=\left[\bar{X}_{1} \hat{\gamma}_{01}^{v}-\bar{X}_{01} \hat{\gamma}_{01}^{v}\right]+\left[\bar{X}_{01} \hat{\gamma}_{01}^{v}-\bar{X}_{0} \hat{\gamma}_{0}^{v}\right] \text {. }
$$

Hence, each observation is replaced by its squared difference from the mean. For the influence function of the Gini coefficient see Monti (1981). 
Equation (5) is defined as the "reweighted-regression" decomposition. However, this decomposition entails both a specification and a reweighting error. Then, the "pure" composition effect is estimated as:

$$
\Delta_{X, p}^{v}=\left(\bar{X}_{01}-\bar{X}_{0}\right) \hat{\gamma}_{0}^{v}
$$

and the "pure" coefficient effect as:

$$
\Delta_{S, p}^{v}=\bar{X}_{1}\left[\hat{\gamma}_{1}^{v}-\hat{\gamma}_{01}^{v}\right]
$$

As in Fortin et al. (2011), "the total reweighting error (...) corresponds to the difference between the Total (...) [composition effect] across the classic OB and the reweightedregression decomposition. (...) The total specification error (...) corresponds to the difference between the Total (...) structure [effect] across the classic OB and the reweighted-regression decomposition" (Fortin et al., 2011, p. 81). In practice, the decomposition is carried out by means of two OB decompositions:

1) a decomposition in which we consider the sample at period 1 and the counterfactual sample to get the pure structure effect. The composition effect of this decomposition is the reweighting error;

2) a decomposition with the counterfactual sample and the sample at period 0 , which allows deriving the pure composition effect. The structure effect of this decomposition is the specification error.

It is worth underlying that the strict exogeneity condition, usually invoked in the standard Oaxaca-Blinder decomposition, is not necessary for the identification of the decomposition terms within this framework, and can be substituted with the less severe ignorability assumption. Under this hypothesis, the expected value of residuals conditional on $X$ need not be zero; the only requirement is that it has to be the same in the two time periods, an assumption that in our context can be considered as reasonable. Moreover, under this assumption, it is possible to give a causal interpretation to the decomposition results, in particular to the structure effect (Fortin et al., 2011).

As a final remark, note that other decomposition methodologies of happiness inequality have been considered in the literature. Ferrer-i-Carbonell and Van Praag (2006) decompose the variance of income satisfaction by means of a stepwise regression. They also consider the standard variance decomposition between and within East and West Germany. Dutta and Foster (2011) measure the gross contribution of gender, race and region to happiness inequality, by using the methodology to measure inequality for ordinal variables proposed by Allison and Foster (2004). However, both approaches do not allow to decompose the overall 
change in happiness inequality into the coefficient and covariate effects. Stevenson and Wolfer (2010) propose to decompose happiness inequality based on the decomposition approach introduced by Lemieux (2002). This methodology allows only to identify the aggregate contribution of changes in regression coefficients, distribution of covariates, and residuals, while the detailed decomposition, i.e. the contribution of each covariate, is not identified.

\section{The econometric analysis: results}

The econometric analysis is divided into two parts. In the first one, we investigate the cross-sectional impact of standard happiness drivers on happiness inequality, at the beginning and at the end of the sample period, by means of the RIF regressions. We make use of two inequality indices, the variance, which represents a standard measure of distributional inequality, and the Gini index, as robustness check. In the second step, we apply the decomposition analysis to quantify the relevance of composition and coefficient effects in affecting the observed changes in happiness inequality.

As for the Gini index, there are at least two main additional methodological concerns. The first, which is actually a minor concern, regards the fact that happiness is not "transferable", while the Gini index is usually defined over transferable variables. ${ }^{18}$ However, it has been observed that this definition and interpretation of may be too literal (Petrie and Tang, 2008), hence the transferability of a variable is not essential for the definition and the measurement of inequality with the Gini index.

The second concern is more crucial. When dealing with bounded variables, as happiness, the measurement of inequality by means of the Gini index is underestimated. In fact, the hypothetical situation in which one individual owns the total amount of happiness is not attainable, since the happiness index is upper limited by ten (Wagstaff et al., 1991; Petrie and Tang, 2008; Erreygers, 2009). This means that with bounded variables the theoretical maximum level of inequality is smaller that the one derived with transferable variables. One possible solution is to standardize the Gini index by using the maximal attainable Gini index for bounded variables, as suggested by Petrie and Tang (2008) to measure health satisfaction inequality. ${ }^{19}$ For the purpose of this paper, this option is not feasible since the influence function for a standardized Gini index is not available in the statistic literature. However, we claim that applying the FFL decomposition to the Gini index can anyway represent an

\footnotetext{
${ }^{18}$ More in general, this remark can be applied to the measurement of happiness inequality, per se.

${ }_{19}$ To provide the intuition concerning the standardized Gini index, assume a population of 10 individuals in which the sum of happiness levels is 40. Is such a case, Petrie and Tang (2008) identify the maximum of the reachable happiness inequality as the case where 4 people were associated to the maximum level of happiness (10) and the other 6 to a value of happiness equal to zero.
} 
interesting robustness check for the analysis computed on the variance, for three main reasons. First, when computing the standardized Gini index as proposed by Petrie and Tang (2008) we find that the dynamics of the standardized Gini coefficients confirms very closely the one observed by the Gini index, with an increase in happiness inequality of about $6 \%$. Second, using our data for Germany we find that the Gini index underestimates the standardized Gini index of around $45 \%$ in both periods, suggesting that the underestimation does not differ over time. Third, it is important to stress that the numerator of the Gini index is the same as the one of the standardized Gini index, the only difference being the denominator, i.e. the two indexes are the same apart from a scale factor.

In such a framework, we claim that the composition and wage structure effect are meaningful, even if they have to be interpreted as the impact of each single covariate or coefficient on the variation of the Gini index, and not of the standardized Gini index. Interestingly, as we will show in the following sections, the results derived by applying the FFL decomposition to the Gini index are very close to the ones derived for the variance.

\subsection{First step: RIF regressions and the identification of the drivers of cross sectional happiness inequality}

Table 2 reports the results of the RIF regressions for the two periods examined separately (1991-92-93 and 2005-06-07), for the variance and for the Gini index. Coefficients measure the impact of each covariate on the inequality measure considered. While there are many contributions concerning the determinants of happiness levels, there is very little evidence about the determinants of happiness inequality. For this reason, this first step of the analysis represents an important finding of the paper per se.

With regard to the contribution of each single covariate on the variance of happiness, education has a significant and monotonically negative impact, regardless the period observed (see Table 2 and Section 5 for a more detailed discussion of this finding). An intuition of what is behind this econometric result is given by the analysis of the histograms of the life satisfaction distribution for low, medium and high education levels (Figure 1): the comparison between low and high education happiness distribution clearly shows that higher education is related to a reduction in the density of both the left and the right tail (i.e. individuals with very low or very high satisfaction scores). This evidence is also consistent with the fact that the happiness variance decreases in the level of education, and that this relation is steeper 
in 2005-07 (Figure 2). It is also worth noting that happiness inequality widened among educational groups in the US as well (Stevenson and Wolfers, 2008).

As for income coefficients, it is possible to observe that, with respect to the omitted category (the first income quintile), an increase in income entails a negative impact on happiness inequality. This effect is stronger for the top income quintile, especially in 2005-07. The inspection of histograms of life satisfaction for different income quintiles (Figure 3) shows that the distribution of happiness is much less dispersed in the top than in the bottom income quintile. This is also consistent with the fact that happiness variance is highest for the lowest income category and, as long as income increases happiness inequality decreases (Figure 4). As in the case of education, this relation is slightly steeper in 2005-2007.

Being relatively poor has, as expected, a positive effect on happiness inequality in the two periods, while being relatively rich entails a negative and slightly significant impact on happiness inequality in the first period, and it is not significant in the second.

As for the employment status, being employed reduces happiness inequality, while being unemployed has a positive effect, and the effect of being retired is never significant. As it can be seen in Figure 5, trends of variance indexes computed by employment status in the two periods examined resemble those of corresponding RIF regression coefficients.

With regard to the effect of age on happiness inequality, we observe a concave trend, first increasing until the 45-54 age class, then decreasing. The effect is always significant only for individuals aged from 35 to 54, i.e. happiness in these age categories displays a large variability that increases over time. The reverse U-shape of the relation between age and happiness inequality is consistent with the time pressure explanation that concerns mainly prime aged individuals (Engfer, 2009). ${ }^{20}$ There is also a remarkable increase in the age effect for the elderly, in 2005-07, with respect to 199193. The reverse U-shape effect can also be seen in Figure 6, where variance indexes by age classes are reported.

\footnotetext{
${ }^{20}$ Our finding closely resembles the often documented U-shaped relationship between age and happiness levels (among others, Frijters and Beatton, 2008 and Van Landeghem, 2008). Furthermore, a possible related rationale for these findings is that, due to time pressure, life satisfaction of working adults depends almost exclusively on their job and relational satisfaction within the household, since not much time is left for the rest. Different patterns are observed for students and retired individuals, who have more leisure time that can be dedicated to activities that compensate for lack of satisfaction in other life dimensions, thereby stabilizing the happiness distribution.
} 
Living in the East Länders increases inequality, but the effect decreases over time. The disabled worker status has a negative impact on both indices. ${ }^{21}$ Note that its effect falls dramatically in 2005-07 in variance regression estimates.

Being divorced or separated, with respect to being single, has a significant positive effect on inequality in both periods. Having no children significantly increases happiness inequality only in the second period.

Finally, being house owner and having a saving account reduces happiness inequality, as expected.

As robustness check in Table 2 we also report the RIF regression using the Gini index. It is reassuring to note that there are no important differences with respect to the coefficients computed in the variance analysis, i.e. same signs and statistically significance, and similar magnitude once taking into account the different scale between the two inequality indexes.

\subsection{Second step: Decomposition results}

The results of the decomposition analysis of the Variance are reported in Table 3, which includes also the decomposition results for the Gini index as robustness check. As a general remark, it is important to underline that the composition effect almost entirely explains the variation of variance over time, while coefficient effect is never significant, as well as the contribution of almost all covariates to the coefficient effect. ${ }^{22}$ This suggests that the effects of the determinants of happiness inequality remain stable over time. For these reasons, we focus our comments on the analysis of the composition effect. ${ }^{23}$

From an economic point of view, three main findings emerge. First, high education negatively affects the variation of happiness inequality. Had only the shares of education levels changed over time, the variance of happiness inequality would have

\footnotetext{
${ }^{21}$ Note that disability has gradually become in Germany a shock absorber in the labour market. In principle, disability benefits are provided by the German system to workers of all ages not able to carry on a regular employment. When the inability is complete the individual is entitled to the disability pension ("Erwerbsunfühigkeitsrente", EU). However also a person that can work only half or less- of the time, compared to a healthy person, may receive two-thirds of old age benefits ("Berufsunfähigkeitsrente", BU). In the 1970s and early 1980s, the rule has been interpreted broadly so that disability became the most relevant pathway to retirement for civil servants (in the year 1999 $47 \%$ of retired used disability retirement). See Börsch-Supan and Wilke (2004) for details on this issue.

${ }^{22}$ Note also that the errors components are not statistically different from zero, meaning that the linear approximation holds true and that the reweighing procedure works fine.

${ }^{23}$ Given the evidence of a significant drop in self reported life satisfaction as an individual is in the panel for a long period (Frijters and Beatton, 2008) -already mentioned in footnote 7- we control as a robustness check for the individual "seniority" in the decomposition analysis, i.e. the number of years of participation to the survey, and results are largely the same.
} 
decreased by 0.03 ( $12 \%$ of the overall between period change). This is due to the combination of two facts. The first is the increase in the shares of medium and high education, as documented in Table 1. The second is that having a medium or high level of education (with respect to the omitted category, low education) has a negative impact on happiness inequality, as can be seen from RIF regression results (Table 2). It is also worth noting that this result is robust to the definition of the education variables. We also used the variable 'year of education' in terciles categories, and results (available upon request) were even stronger.

Second, interesting results come out from the labour market variables. The increase in unemployment rates over time (from $7.1 \%$ to $9.7 \%$ ) has a strong and positive impact on the evolution of happiness inequality (more than $30 \%$ of the variance variation), due to the fact that being unemployed increase happiness inequality in a cross-section perspective (Table 2$){ }^{24}$

Third, income redistribution has a slight overall negative impact on happiness inequality changes, since the positive effect of the second and third income categories is more than counterbalanced by the negative value of the top income quintile. This means that the strong increase in wage and income inequality observed in Germany (Dustmann et al 2008, Gernandt and Pfeiffer, 2007) - and in our data as well - cannot be considered as one of the driving forces of the increase in happiness inequality. This also suggests that the non-pecuniary drivers of life satisfaction, such as the distribution of education, age, and employment status (conditional on income) are behind the increase in happiness inequality. Our result is also consistent with the findings derived by Stevenson and Wolfers (2008) for the US: opposite dynamics over time are observed for income and happiness inequality, suggesting - also for the US case - the importance of the role of non-pecuniary drivers in shaping the evolution of happiness inequality.

Another interesting finding is that, after controlling for individual income, the relative income positively affects the increase of happiness inequality. More specifically, the sum of the coefficients associated to being relatively poor and being relatively rich is equal to 0.23 and explains almost $9 \%$ of the Variance increase. This can be considered as a preliminary test of Van Praag (2011), which stresses the

\footnotetext{
${ }^{24}$ Note that the coefficient effect associated to being unemployed is the only one that is statistically different from zero, and it is in magnitude similar but negative with respect to the composition effect. This suggests that had only the coefficient of unemployment kept constant, happiness inequality would have decreased, consistently with the fact that the unemployment coefficient gets smaller over time (Table 2). This might be due to the fact that unemployed may have become progressively accustomed to unemployment over time, and this might have entailed a decreasing impact on unemployment in the RIF coefficients (Table 2) and on the variation of Happiness inequality (Table 3).
} 
importance of relative living conditions to address happiness inequality issues. However, note that this result might depend on the way the reference group has been computed.

Furthermore, the reduction in the share of those who have a saving account positively affects happiness inequality. This is due to the fact that, according to the RIF regression in Table 2, having a saving account is associated to lower happiness inequality, and since the share of individuals with a saving account decreased over time the impact of this variable on the evolution of happiness inequality is positive. Note however that, the other proxy for financial conditions and wealth, house ownership, is slightly significant in the decomposition, negative, and much smaller in magnitude.

Demographic changes are noticeable only for the 35-45 and 45-54 age classes, which have both a positive effect on the evolution of the happiness inequality (15\% of total Variance variation over time), consistently with findings emerging from RIF regressions in Table 2. Further, from descriptive statistics in Table 1 it emerges that the size of these cohorts increased, because of the ageing of the German population and of the baby boomers. Hence, the rising happiness inequality is explained by the higher population share ageing from 35 to 54 years, which displays higher happiness inequality, as confirmed also by Figure 6. As explained above, these findings could be related to time pressure effects.

As far as marital and familiar status, being married is the only covariate with a significant and positive impact on the dynamics of happiness inequality (with respect to the omitted category, 'never been married'). RIF regressions show that this variable is associated with lower levels of happiness inequality. Hence, since the share of married individuals strongly decreases, the impact on happiness inequality is positive and explains about $14 \%$ of the total change in the variance. A smaller impact is derived for being disabled, whose share increased only slightly over time.

Finally, the slight decrease in the share of those who live in the East Länders entails a negative effect on the variation of happiness inequality, since living in this area is positively associated to higher happiness inequality (Table 2$){ }^{25}$ Since the socioeconomic differences between West and East Germany are still pronounced, we have also carried out two separate decomposition exercises for the two macro regions. The findings for the whole country are mainly driven by the West Germany. ${ }^{26}$ This could

\footnotetext{
${ }^{25}$ A reasonable interpretation is that individuals in East Germans - after the fall of the communist regime and in a more competitive and less protected environment - suffers more from relative comparisons.

${ }^{26}$ Decomposition results for West Germany are very close to the ones derived for the whole country. The results computed separately for West and East Germany are available from the authors upon request.
} 
be due to the small number of observations for East Germany (around 20\% of the total), which might affect the significance of composition or coefficient effects when applying the decomposition for this region. Since a more in-depth analysis of the drivers of happiness inequality in East Germany is beyond what achievable with our data, we discard this issue in the rest of the paper.

In Table 3 we also report the decomposition results when using the Gini index as distributional measure. Interestingly, the main results are very close to the ones derived by using the variance, providing robustness to the analysis. In fact, using the Gini index we can confirm that changes in the index over time are mainly due to changes in covariates and not to changes in coefficients. Moreover, we derive results substantially similar to what previously observed, including the negative impact of education, the overall slight negative impact of income inequality, the positive impact of being unemployed and the inverse U-shape impact of age. Further, also the shares of happiness inequality trends explained by the changes in the covariates are very close to the ones derived for the variance.

\section{Further discussion of the results: the symmetric tail-reducing effect of education}

The negative composition impact of education on the dynamics of happiness inequality is one of the main finding of the paper, which deserves further investigation. In Table 4 we report the results of two separate logistic regressions, to detect which covariates affect the probability of falling in the upper or lower tail of life satisfaction distribution. We recode as Low happiness a degree of life satisfaction lower or equal to 5, while High happiness corresponds to a degree higher than 8 . Overall, results are consistent with previous findings: education affects negatively the probability to fail in the low happiness, while it is not significant with respect to the probability to being fully satisfied.

A general interpretation for the negative impact of higher education on the low tail of happiness inequality is that education enables individuals to increase their set of functionings and, through them, to enhance their capabilities. ${ }^{27}$ Since functionings may be defined as "various things a person may value being or doing" (Sen, 1999, p.75), it is reasonable to relate the increase of functionings, and the enhancement of capabilities, to higher life satisfaction. All this considered, if we conveniently assume that an important part of happiness inequality is explained by fat low tails (higher share of individuals with very low life satisfaction scores), we can argue that

\footnotetext{
${ }^{27}$ Following Sen's definition capabilities are "the alternative combinations of functionings that are feasible for a person to achieve" (Sen, 1999, p.75).
} 
education, by enlarging the set of functionings and capabilities, reduces the probability that individuals lack of sufficient resources to avoid the "low satisfaction trap". Just as examples, more educated individuals are more likely to find satisfactory and well remunerated jobs, are relatively more able to care about their health and benefit more from leisure since they can appreciate a wider range of cultural products. ${ }^{28}$

However, the impact of education on the probability to being fully satisfied is not statistically significant. How can this less expected effect be interpreted? Our claim is that education raises aspiration levels and therefore, everything else being equal, the gap between realisations and aspirations. ${ }^{29}$ In such a framework, the positive spillovers related to education and aspirations could be offset by the gap between realisations and aspirations.

Going back to the decomposition results, how can we explain the reducing impact of education on happiness inequality, and the relation between education and happiness inequality that becomes stronger over time (Figure 2)? Since what we are measuring in the decomposition is a direct effect of education, net of the indirect effect via income generated by "returns to schooling", ${ }^{30}$ our findings can hardly be explained by the rise in skill wage differentials due to global integration and technological change occurred in the labour markets since the nineties. ${ }^{31}$ A possible interpretation for the increasing direct effect of education on happiness inequality might concern the higher and increasing capability of educated individual to enjoy the leisure time. This in turn can be related to the diffusion of the web and of new technologies which provides, especially for skilled individuals, both an amount of additional information (together with an increase in its speed of circulation) and new tools to enjoy leisure and culture.

\footnotetext{
${ }^{28}$ Hayward et al (2005) document that "Educational attainment is positively associated both with health status and with healthy lifestyles. For example, in the 1996-97 [Canadian] National Population Health Survey, only 19\% of respondents with less than high school education rated their health as 'excellent', compared with almost $30 \%$ of university graduates. Self-rated health, in turn, has been shown to be a reliable predictor of health problems, health-care utilization, and longevity. From a health determinant perspective, education is clearly a good investment that can reduce longterm health care costs" (pp.37-38).

${ }^{29}$ The point is well resumed by Frey and Stutzer (2002b, p. 59) claiming that "the level of education, as such, bears little relationship to happiness. Education is highly correlated with income [...]. Education may indirectly contribute to happiness by allowing a better adaptation to changing environments. But it also tends to raise aspiration levels. Further, it has been found that the highly educated are more distressed than the less educated when they are hit by unemployment (Clark and Oswald, 1994)". Also Ferrante (2009) discusses how "systematic frustration over unfulfilled expectations can be connected to people's educational achievement".

${ }^{30}$ For a review of this literature see Card (1999).

${ }^{31}$ See Acemoglu (2002) for a survey regarding the impact of technological change and globalization on the labour market. See Dustmann et al (2008) for an analysis of the impact of technological change and globalization on the German wage structure.
} 


\section{Conclusions}

The contribution of our paper to the happiness literature lies in the investigation of determinants of both levels and over time changes of happiness inequality, and in the decomposition of happiness inequality changes in composition and coefficient effects. By applying the methodological approach proposed by Fortin et al. (2011) to the German case in the period 1991-2007, we find what follows.

First, most of the dynamics of happiness inequality is explained by the composition effect, while changes in coefficient effects are almost nil, documenting the invariance across time of what factors (and how much they) make individuals happier.

Second, happiness inequality has risen mainly due to the deterioration of labour market conditions and to a demographic effect (the increase in the middle age cohort population share). These changes have been less than compensated by the increase of the share of highly educated individuals which entails a negative effect on the dynamics of happiness inequality. Further, the increase in income inequality cannot be considered as one of the driver of the increase in happiness inequality, consistently with the US case (Stevenson and Wolfers, 2008).

We claim that the analysis of the drivers of happiness inequality may be useful in terms of policies as well. We argue that the policy makers when deciding redistributive policies can take into account, in addition to standard economic variables such as income and wage levels and inequality, also pieces of information related to happiness inequality.

From the application on the German case, our main policy suggestion is that education is a crucial factor for social cohesion. Education has a direct effect in reducing happiness inequality and such effect has become steeper over time. Further, higher education is associated to a lower probability of falling in the low satisfaction trap - presumably for its effect on health, individual productivity and the capacity of enjoying leisure - while not increasing the probability of being in the upper tail of life satisfaction - due to a possible frustration of aspirations. The role of education on happiness inequality is probably the most important result of our paper. The economic literature has deeply investigated the impact of this variable on individual earnings and as a factor of macroeconomic conditional convergence. As far as we know, this is the first time that such variable, net of its role on personal income, has been found to affect happiness inequality and, as such, to be a driver of social cohesion.

Beyond education, we also documented that labour market conditions have a direct smoothing effect on happiness inequality. This evidence provides straightforward policy implications: measures aiming at increasing (decreasing) the employment 
(unemployment) rate generate, apart from the clear cut effects on economic performance, additional spillovers in terms of reduction of happiness inequality and, in turn, of enhanced social cohesion. 


\section{References}

Acemoglu, D. (2002), "Technical Change, Inequality, and the Labor Market", Journal of Economic Literature, 40, 7-72.

Alesina, A., Di Tella, R., MacCulloch, R. (2004), “Inequality and happiness: Are Europeans and Americans different", Journal of Public Economics, 88, 2009-2042.

Allison, R.A., Foster, J. (2004), "Measuring health inequality using qualitative data", Journal of Health Economics, 23, 505-524.

Barsky, R., Bound, J., Charles, K., Lupton, J. (2002), “Accounting for the Black-White Wealth Gap: A Nonparametric Approach", Journal of the American Statistical Association, 97(459), 663-673.

Becchetti, L., Savastano, S. (2010), "The money-happiness relationship in transition countries: evidence from Albania", Transition Studies Review, 17(1), 39-62.

Beegle, K., Himelein, K., Ravaillon, M. (2011), "Frame-of-Reference Bias in Subjective Welfare Regressions", Journal of Economic Behavior $\mathcal{E}$ Organization, in press, doi:10.1016/j.jebo.2011.07.020.

Blinder, A. (1973), “Wage discrimination: Reduced form and structural estimates", Journal of Human Resources, 8(4), 436-455.

Bollen, K.A., Barb, K.H. (1981), "Pearson's R and coarsely categorized data", American Sociological Review, 46, 232-239

Bollen, K.A., Barb, K.H. (1983), “Collapsing variables and validity coefficients (reply to O'Brien)", American Sociological Review, 48, 286.

Börsch-Supan, A., Wilke, C.B. (2004), "The German Public Pension System: How it Was, How it Will Be", NBER Working Paper 10525.

Brown, M.E. (1996). "The Causes and Regional Dimensions of Internal Conflict," in Brown, M. (ed.), The International Dimensions of Internal Conflict, Cambridge, MA: MIT Press.

Card., D. (1999), “The causal effect of education on earnings" In O. Ashenfelter and D. Card (eds.) Handbook of Labor Economics, vol. 3, New York: Elsevier Science.

Cantril, H. (1965), The pattern of human concern, Rutgers University Press.

Chi, W., Li, B. (2008), "Glass ceiling or sticky floor? Examining the gender earnings differential across the earnings distribution in urban China, 1987-2004", Journal of Comparative Economics, 36(2), 243-263.

Chin-Hon-Foei, S. (1989), "Life Satisfaction in the EC Countries, 1975-1984", in: Veenhoven, R. (ed.): “Did the Crisis Really Hurt?" Universitaire Pers Rotterdam, Netherlands, 24 43

Clark, A.E., Frijters, P., Shields, M.A. (2006), "Income and Happiness: Evidence, Explanations and Economic Implications", Paris Jourdan Sciences Economiques, working paper 2006-24.

Clark, A., Krinstensen, N., Westengaard, N. (2009), “Economic Satisfaction and Income Rank in Small neighbourhoods", Journal of the European Economic Association, 7(2-3), 519-527.

Clark, A., Oswald, A. (1994), “Unhappiness and Unemployment”, The Economic Journal, 104(424), 648-659.

Di Nardo, J., Fortin, N. M., Lemieux, T. (1996), “Labor market institutions and the distribution of wages, 1973-1992: A semiparametric approach", Econometrica, 64(5), 1001-1044.

Di Tella, R., MacCulloch, R. (2006), "Some Uses of Happiness Data in Economics", Journal of Economic Perspectives, 20(1), 25-46. 
Dolan, P., Peasgood, T., White, M. (2008), "Do we really know what makes us happy? A review of the economic literature on the factors associated with subjective well being", Journal of Economic Psychology, 29, 94 - 122.

Dusenberry, J. (1949), Income, Saving and Theory of Consumer Behavior, Harvard University Press, Cambridge.

Dustmann, C., Ludsteck, J., Schönberg, U. (2008), "Revisiting the German Wage Structure", The Quarterly Journal of Economics, MIT Press, vol. 124(2), 843-881.

Dutta, I., Foster, J. (2011), "Inequality of Happiness in US: 1972-2008", The School of Economics Discussion Paper Series, The University of Manchester.

Engfer, U. (2009), "Restructuring of activities and rising satisfaction with time use after retirement: Findings from the German time budget survey", paper presented at the 2009 ISQOLS Conference, Florence 2009.

Erreygers, G. (2009), "Correcting the Concentration Index", Journal of Health Economics, 28(2), 504-515

Ferrante, F. (2009), "Education, Aspirations and Life Satisfaction", Kyklos, Vol. 62, No. 4, 542-562.

Ferrer-i-Carbonell, A., Frijters, P. (2004), “How Important is Methodology for the estimates of the determinants of Happiness?", Economic Journal, 114, 641-659.

Ferrer-i-Carbonell, A, Van Praag, B. (2003), "Income Satisfaction Inequality and its Causes", Journal of Economic Inequality, vol. 1(2), 107-127.

Firpo, S., Fortin, N.M., Lemieux, T. (2007), “Decomposing wage distributions using recentered influence function regressions", Unpublished manuscript. PUC-Rio and $\mathrm{UBC}$

Firpo, S., Fortin, N.M., Lemieux, T. (2009), "Unconditional quantile regressions", Econometrica 77(3), 953-973.

Firpo, S., Fortin, N.M., Lemieux, T. (2011), “Occupational Tasks and Changes in the Wage Structure", IZA working paper no. 5542.

Fortin, N., Lemieux, T., Firpo, S. (2011) "Decomposition Methods in Economics", in Ashenfelter O., Card D., (eds), Handbook of Labor Economics, Elsevier, Vol. 4, Part A, 1102.

Frijters, P., Beatton, T. (2008), "The mystery of the U-shaped relationship between happiness and age", National Centre for Econometric Research Working Paper Series No.26.

Frijters, P., Shields, M.A., Haisken-DeNew, J.P. (2004a), “Money Does Matter! Evidence from Increasing Real Incomes in East Germany Following Reunification". American Economic Review, 94, 730-741.

Frijters, P., Shields, M.A., Haisken-DeNew, J.P. (2004b),. "Changes in the Pattern and Determinants of Life Satisfaction in Germany Following Reunification". Journal of Human Resources, 39, 649-674

Frey, B.S., Stutzer, A. (2002a), “What can economists learn from happiness research?” Journal of Economic Literature, 40, 402-435.

Frey, B. S., Stutzer, A. (2002b), Happiness and Economics. How the Economy and Institutions Affect Well-being, Princeton University Press, Princeton, New Jersey.

Gernandt, J, Pfeiffer, F. (2007), "Rising Wage Inequality in Germany", Journal of Economics and Statistics (Jahrbuecher fuer Nationaloekonomie und Statistik), 227(4), 358-380

Graham, C., Felton, A. (2006), "Inequality and happiness: Insights from Latin America", Journal of Economic Inequality, 4(1), 1569-1721.

Guimaraes, B., Sheedy, K.D. (2010) "A model of equilibrium institutions", working paper LSE 
Gurr, T. R. (1994). "Peoples Against States: Ethnopolitical Conflict and the Changing World System," International Studies Quarterly, 38, 347-377.

Guven, C., Senik, C., Stichnoth, H. (2009) "You Can't Be Happier than Your Wife: Happiness Gaps and Divorce", IZA working paper n. 2988.

Hampel, F. R. (1974), "The influence curve and its role in robust estimation", Journal of the American Statistical Association, 69(346), 383-393.

Harsanyi, J.C. (1955), "Cardinal Welfare, Individualistic Ethics, and Interpersonal Comparisons of Utility", The Journal of Political Economy, 638(4), 309-321.

Hayward, K., Pannozzo, L., Colman, R. (2005), “Developing Indicators for the Educated Populace Domain of the Canadian Index of Wellbeing", Interim Report, GPI Atlantic, Halifax

Hirsch, F. (1976), Social Limits of Growth. Harvard University Press, Cambridge, Massachusetts.

Hirschman, A., (1973), "The Changing Tolerance for Income Inequality in the Course of Economic Development", Quarterly Journal of Economics, 87, 544-566.

Idler, E., Benyamini, Y. (1997), "Self-rated health and mortality: a review of twenty-seven community studies", Journal of Health and Social Behavior, 38(1), 21-37.

Jiang, S., Lu, M., Sato, H. (2009), "Happiness in the dual society of urban China: Hukou identity, horizontal inequality and heterogeneous reference", Global COE Hi-Stat Discussion Paper Series n. 20.

Lemieux, T. (2002), "Decomposing Changes in Wage Distributions: A Unified Approach", Canadian Journal of Economics, 35, 646-88.

Malthus, T. (1798), An Essay on the Principles of Population, J. Johnson, London.

Marshall, A. (1890), Principles of Economics. MacMillan, London.

Monti, A. C., (1991), "The Study of the Gini Concentration Ratio by Means of the Influence Function", Statistica, 51, 561-577.

Oaxaca, R. (1973), "Male-female wage differentials in urban labor markets", International Economic Review, 14(3), 693-709.

Ott, J. C. (2010), “Greater Happiness for a Greater Number: Some Non-controversial Options for Governments", Journal of Happiness Studies, 11(5), 631-647.

Ovaska, T., Takashima, R. (2010), “Does a Rising Tide Lift All the Boats? Explaining the National Inequality of Happiness", Journal of Economic Issues, , 44(1), 205-224.

Petrie, P., Tang, K.K (2008), “A Rethink on Measuring Health Inequalities Using the Gini Coefficient", Discussion Papers Series 381, School of Economics, University of Queensland, Australia.

Schirle, T. (2009), "Income Inequality Among Seniors in Canada: The Role of Women's Labour Market Experience", CLSRN Working Paper No. 51.

Scitovsky, T. (1974), "Inequalities: Open and hidden, measured and immeasurable", Annals of American Academy of Political and Social Science (AAPSS).

Scitovsky T. (1976), The Joyless Economy, Oxford University Press: Oxford.

Sen, A.K. (1999), Development as Freedom, Oxford University Press: Oxford.

Senik, C. (2004) “Relativizing Relative Income,” DELTA Working Papers 2004-17

Srinivasan, V., Amiya, K.B. (1989), "The metric quality of ordered categorical data," Marketing Science, 8(3), 205-230

Stevenson, B, Wolfers, J. (2008), "Happiness Inequality in the United States", Journal of Legal Studies, 37(2), 33-79 
Stiglitz, J.E., Sen, A., Fitoussi, J.P. (2009), "Report by the commission on the measurement of economic performance and social progress", Commission on the Measurement of Economic Performance and Social Progress, Paris.

Tullock, G. (1971), “The paradox of revolution”, Public Choice, 11, 89-100

Van Landeghem, B.G.M. (2008), "Human Well-Being over the Life Cycle: Longitudinal Evidence from a 20-Year Panel“. LICOS Centre for Institutions and Economic Performance, Discussion Paper 213/2008.

Van Praag, B.M.S. (2007). "Perspectives from the Happiness Literature and the Role of New Instruments for Policy Analysis", IZA Discussion Paper No. 2568.

Van Praag, B.M.S. (2011). “Well-being Inequality and Reference Groups: An Agenda for New Research", Journal of Economic Inequality, vol. 9(1), 111-127.

Van Praag, B.M.S. and Ferrer-i-Carbonell, A. (2004). Happiness Quantified, A Satisfaction Calculus Approach, Oxford University Press.

Van Praag, B.M.S. and Ferrer-i-Carbonell, A. (2006). “An Almost Integration-free Approach to Ordered Response Models", Tinbergen Institute Discussion Paper TI 2006-047/3.

Veblen, T. (1899), The Theory of the Leisure Class, Dover Publications, New York.

Veenhoven, R. (1990), "Inequality in happiness, inequality in countries compared between countries", Paper presented at the12th Work Congress of Sociology, Madrid, Spain.

Veenhoven, R. (2005), "Return of Inequality in Modern Society? Test by Dispersion of LifeSatisfaction Across Time and Nations", Journal of Happiness Studies, 6(4), 457-487.

Veenhoven, R. (2009), World Database of Happiness, collection Happiness in Nations, Nation Report Germany (DE), viewed at http:// worlddatabaseofhappiness.eur.nl on 2010-1229.

Wagstaff A., Pact P., van Doorslaer E. (1991), “On the measurement of inequalities in health", Social Science \& Medicine, 33(5), 545-557. 
Tables

Table 1. Changes in the mean of covariates over time

\begin{tabular}{lrr}
\hline & $1991-1992$ & $2006-07$ \\
\hline Female & 0.505 & 0.521 \\
Low Educated (ISCED 1-2) & 0.196 & 0.127 \\
Medium Educated (ISCED 3-4) & 0.566 & 0.591 \\
High Educated (ISCED 5-6) & 0.238 & 0.282 \\
Age 18_24 & 0.105 & 0.085 \\
Age 25_34 & 0.263 & 0.195 \\
Age 35_44 & 0.225 & 0.282 \\
Age 45_54 & 0.208 & 0.242 \\
Age 55_64 & 0.199 & 0.196 \\
Disabled & 0.079 & 0.095 \\
Married & 0.615 & 0.523 \\
No more married & 0.131 & 0.159 \\
Children in the household & 0.640 & 0.666 \\
Income 1 (first quintile) & 0.234 & 0.227 \\
Income 2 (second quintile) & 0.216 & 0.175 \\
Income 3 (third quintile) & 0.205 & 0.194 \\
Income 4 (fourth quintile) & 0.195 & 0.208 \\
Income 5 (fifth quintile) & 0.149 & 0.196 \\
Relatively poor & 0.286 & 0.321 \\
Relatively median & 0.483 & 0.487 \\
Relatively rich & 0.232 & 0.193 \\
Living in the East & 0.209 & 0.204 \\
Employed & 0.734 & 0.748 \\
Unemployed & 0.071 & 0.097 \\
Retired & 0.106 & 0.075 \\
House owner & 0.446 & 0.481 \\
Having a saving account & 0.815 & 0.695 \\
\hline \hline GSOEP Weigted & &
\end{tabular}

GSOEP Weighted data. For variable definitions see Table 1A in the Appendix. 
Table 2. RIF Regressions for the two periods, for the Variance and the Gini index.

\begin{tabular}{|c|c|c|c|c|c|c|c|c|}
\hline & \multicolumn{4}{|c|}{ Variance } & \multicolumn{4}{|c|}{ Gini } \\
\hline & \multicolumn{2}{|c|}{$1^{\text {th }}$ Period } & \multicolumn{2}{|c|}{$2^{\text {th }}$ Period } & \multicolumn{2}{|c|}{$1^{\text {th }}$ Period } & \multicolumn{2}{|c|}{$2^{\text {th }}$ Period } \\
\hline & coeff & t-stud & coeff & t-stud & coeff & t-stud & coeff & t-stud \\
\hline Female & -0.019 & -0.25 & -0.275 & $-4.35 * * *$ & -0.001 & -0.48 & -0.008 & $-4.99 * * *$ \\
\hline Medium_education & -0.363 & $-3.77 * * *$ & -0.223 & $-2.31 * *$ & -0.013 & $-5.35 * * *$ & -0.012 & $-4.63 * * *$ \\
\hline High_education & -0.449 & $-3.76 * * *$ & -0.418 & $-3.72 * * *$ & -0.015 & $-4.97 * * *$ & -0.021 & $-7.27 * * *$ \\
\hline Age18_24 & -0.311 & $-2.23 * *$ & -0.258 & $-1.97 *$ & -0.010 & $-2.95 * * *$ & -0.010 & $-2.85 * * *$ \\
\hline Age35_44 & 0.265 & $2.45 * * *$ & 0.504 & $5.18 * * *$ & 0.012 & $4.67 * * *$ & 0.023 & $8.94 * * *$ \\
\hline Age45_54 & 0.824 & $6.90 * * *$ & 0.942 & $8.71 * * *$ & 0.025 & $8.48 * * *$ & 0.040 & $14.32 * * *$ \\
\hline Age55_64 & 0.116 & 0.82 & 0.168 & 1.33 & 0.003 & 0.89 & 0.010 & $3.08 * * *$ \\
\hline Disable & 0.902 & $6.35 * * *$ & 1.504 & $13.28 * * *$ & 0.033 & $9.26 * * *$ & 0.054 & $18.33 * * *$ \\
\hline Married & -0.399 & $-3.40 * * *$ & -0.168 & $-1.79 *$ & -0.011 & $-3.91 * * *$ & -0.010 & $-4.16 * * *$ \\
\hline No more married & 0.145 & 1.00 & 0.317 & $2.87 * * *$ & 0.006 & $1.69 *$ & 0.006 & $2.14 * *$ \\
\hline No child in the $\mathrm{HH}$ & 0.116 & 1.20 & 0.327 & $4.12 * * *$ & 0.004 & $1.71 *$ & 0.012 & $5.71 * * *$ \\
\hline Inc_2 & -0.366 & $-3.13 * * *$ & -0.443 & $-4.15 * * *$ & -0.015 & $-5.15 * * *$ & -0.016 & $-5.60 * * *$ \\
\hline Inc_3 & -0.327 & $-2.47 * * *$ & -0.547 & $-4.79 * * *$ & -0.015 & $-4.45 * * *$ & -0.022 & $-7.44 * * *$ \\
\hline Inc_4 & -0.456 & $-3.02 * * *$ & -0.671 & $-5.36 * * *$ & -0.021 & $-5.51 * * *$ & -0.026 & $-8.10 * * *$ \\
\hline Inc_5 & -0.590 & $-3.23 * * *$ & -0.869 & $-5.92 * * *$ & -0.028 & $-6.10 * * *$ & -0.034 & $-8.86^{* * *}$ \\
\hline Rel_poor & 0.392 & $3.71 * * *$ & 0.442 & $4.94 * * *$ & 0.011 & $4.14 * * *$ & 0.012 & $5.30 * * *$ \\
\hline Rel_rich & -0.220 & $-1.93 *$ & -0.135 & -1.36 & -0.005 & $-1.88 *$ & -0.008 & $-3.30 * * *$ \\
\hline Living in the East & 0.654 & $6.28 * * *$ & 0.201 & $2.48 * * *$ & 0.038 & $14.78 * * *$ & 0.016 & $7.69 * * *$ \\
\hline Employed & -0.362 & $-3.33 * * *$ & -0.557 & $-5.45^{* * *}$ & -0.010 & $-3.78 * * *$ & -0.014 & $-5.15^{* * *}$ \\
\hline Unemployed & 3.055 & $18.51 * * *$ & 2.241 & $16.01 * * *$ & 0.079 & $19.41 * * *$ & 0.073 & $20.01 * * *$ \\
\hline Retired & -0.229 & -1.51 & -0.286 & $-1.90 *$ & -0.004 & -1.13 & -0.004 & -1.05 \\
\hline Owner & -0.290 & $-3.76 * * *$ & -0.102 & -1.47 & -0.012 & $-6.12 * * *$ & -0.008 & $-4.40 * * *$ \\
\hline Saving Acc. & -0.896 & $-9.50 * * *$ & -1.046 & $-15.09 * * *$ & -0.028 & $-11.84^{* * *}$ & -0.033 & $-18.28 * * *$ \\
\hline Constant & 4.461 & $21.09 * * *$ & 4.501 & $24.41^{* * *}$ & 0.178 & $34.05^{* * *}$ & 0.183 & $38.22 * * *$ \\
\hline
\end{tabular}

${ }^{*}$ stands for statistically different from zero at $10 \%,{ }^{* *}$ at $5 \%,{ }^{* * *}$ at $1 \%$. For variable definitions see Table $1 \mathrm{~A}$ in the Appendix. 
Table 3. Decomposition of Life Satisfaction inequality changes: composition and coefficient effects, for Variance and Gini index.

\begin{tabular}{|c|c|c|c|c|c|c|c|c|}
\hline & \multicolumn{4}{|c|}{ Variance } & \multicolumn{4}{|c|}{ Gini } \\
\hline & \multicolumn{2}{|c|}{ Composition } & \multicolumn{2}{|c|}{ Coefficients } & \multicolumn{2}{|c|}{ Composition } & \multicolumn{2}{|c|}{ Coefficients } \\
\hline & coeff & $t$ & coeff & $\mathrm{t}$ & coeff & $\mathrm{t}$ & coeff & $\mathrm{t}$ \\
\hline Female & -0.0005 & -0.18 & -0.1340 & -1.09 & 0.0000 & -0.37 & -0.0042 & -1.34 \\
\hline Medium_education & -0.0089 & $-1.80 *$ & 0.0082 & 0.04 & -0.0003 & $-2.09 * *$ & -0.0005 & -0.10 \\
\hline High_education & -0.0207 & $-2.07 * *$ & -0.0246 & -0.27 & -0.0007 & $-2.91 * * *$ & -0.0027 & -1.29 \\
\hline Age18_24 & 0.0065 & $1.92 *$ & 0.0366 & 1.45 & 0.0002 & $2.39 * * *$ & 0.0010 & 1.59 \\
\hline Age35_44 & 0.0147 & $1.76 *$ & -0.0215 & -0.23 & 0.0007 & $3.13 * * *$ & 0.0007 & 0.29 \\
\hline Age45_54 & 0.0249 & $2.74 * * *$ & -0.1210 & -1.07 & 0.0008 & $3.29 * * *$ & 0.0005 & 0.17 \\
\hline Age55_64 & -0.0003 & -0.12 & -0.0974 & -1.35 & 0.0000 & -0.14 & -0.0003 & -0.15 \\
\hline Disable & 0.0162 & $3.04 * * *$ & 0.0753 & 1.40 & 0.0006 & $3.66^{* * *}$ & 0.0027 & $2.22 * *$ \\
\hline Married & 0.0376 & $2.38 * * *$ & 0.3288 & 1.56 & 0.0011 & $2.39 * * *$ & 0.0061 & 1.19 \\
\hline No more married & 0.0034 & 0.77 & 0.0999 & 1.05 & 0.0001 & 1.30 & 0.0018 & 0.86 \\
\hline No child in the $\mathrm{HH}$ & 0.0044 & 0.94 & 0.1161 & 0.68 & 0.0002 & 1.17 & 0.0037 & 0.86 \\
\hline Inc_2 & 0.0156 & $2.02 * *$ & 0.0261 & 0.33 & 0.0006 & $3.17 * * *$ & 0.0007 & 0.40 \\
\hline Inc_3 & 0.0038 & $1.74^{*}$ & 0.0371 & 0.49 & 0.0002 & $2.40 * * *$ & 0.0001 & 0.07 \\
\hline Inc_4 & -0.0058 & -1.53 & 0.0748 & 0.86 & -0.0003 & $-1.91 *$ & 0.0015 & 0.71 \\
\hline Inc_5 & -0.0311 & $-2.66 * * *$ & 0.0495 & 0.50 & -0.0015 & $-4.98 * * *$ & 0.0010 & 0.40 \\
\hline Rel_poor & 0.0146 & $2.17^{* *}$ & -0.0207 & -0.18 & 0.0004 & $2.40 * * *$ & -0.0005 & -0.22 \\
\hline Rel_rich & 0.0080 & $1.67 *$ & -0.0260 & -0.62 & 0.0002 & 1.48 & -0.0011 & -1.06 \\
\hline Living in the East & -0.0137 & $-2.78 * * *$ & -0.0862 & -1.25 & -0.0008 & $-3.64 * * *$ & -0.0044 & $-2.63 * * *$ \\
\hline Employed & -0.0033 & -0.97 & 0.0519 & 0.27 & -0.0001 & -1.00 & 0.0023 & 0.50 \\
\hline Unemployed & 0.0903 & $4.09^{* * *}$ & -0.1117 & $-1.91 *$ & 0.0024 & $4.18^{* * *}$ & -0.0016 & -1.30 \\
\hline Retired & 0.0068 & 1.07 & 0.0344 & 0.93 & 0.0001 & 0.99 & 0.0006 & 0.76 \\
\hline Owner & -0.0057 & $-1.80 *$ & 0.1187 & 1.20 & -0.0002 & $-1.97 *$ & 0.0013 & 0.51 \\
\hline Saving Acc. & 0.0992 & $5.67 * * *$ & -0.1033 & -0.55 & 0.0031 & $6.54 * * *$ & -0.0035 & -0.77 \\
\hline Constant & & & -0.3438 & -0.41 & & & -0.0041 & -0.23 \\
\hline TOT & 3.4665 & $59.60 * * *$ & 0.2530 & $3.18^{* * * 1}$ & 0.7358 & $3.95 * * *$ & 0.000 & 0.334 \\
\hline Reweighing error & -0.001 & -0.029 & & & 0.000 & 0.334 & & \\
\hline Specification error & 0.031 & 0.321 & & & 0.001 & 0.247 & 0.001 & 0.247 \\
\hline Index change & 0.253 & $3.142 * * *$ & & & 0.009 & $4.15 * * *$ & & \\
\hline
\end{tabular}

"stands for statistically different from zero at $10 \%,{ }^{* *}$ at $5 \%,{ }^{* * *}$ at $1 \%$. Standard errors are computed bootstrapping the whole decomposition procedure (100 replications), as in Firpo et al. (2009). For variable definitions see Table 1A in the Appendix. 
Table 4. Determinants of the probability of falling in the life satisfaction distribution tails

\begin{tabular}{|c|c|c|c|c|}
\hline & \multicolumn{2}{|c|}{ Low happiness } & \multicolumn{2}{|c|}{ High happiness } \\
\hline & Marg.eff. & $t$ & Marg.eff. & $\mathrm{t}$ \\
\hline Female & -0.007 & -1.20 & 0.169 & $4.38 * * *$ \\
\hline Medium_education & -0.039 & $-5.13 * * *$ & 0.000 & 0.00 \\
\hline High_education & -0.053 & $-5.78 * * *$ & 0.023 & 0.36 \\
\hline Age18_24 & -0.025 & $-2.26 * *$ & 0.232 & $3.10^{* * *}$ \\
\hline Age35_44 & 0.067 & $7.99 * * *$ & -0.364 & $-6.40 * * *$ \\
\hline Age45_54 & 0.096 & $10.59 * * *$ & -0.416 & $-6.64 * * *$ \\
\hline Age55_64 & 0.027 & $2.42 * * *$ & -0.126 & $-1.65 *$ \\
\hline Disable & 0.119 & $12.28 * * *$ & -0.410 & $-4.64 * * *$ \\
\hline Married & -0.017 & $-2.00 *$ & 0.262 & $4.13^{* * *}$ \\
\hline No more married & 0.016 & 1.50 & 0.095 & 1.17 \\
\hline No child in the $\mathrm{HH}$ & 0.021 & $3.02 * * *$ & -0.025 & -0.50 \\
\hline Inc_2 & -0.044 & $-5.62 * * *$ & 0.007 & 0.10 \\
\hline Inc_3 & -0.064 & $-6.91 * * *$ & 0.138 & $1.89 *$ \\
\hline Inc_4 & -0.089 & $-8.58 * * *$ & 0.155 & $1.96 *$ \\
\hline Inc_5 & -0.129 & $-9.55 * * *$ & 0.194 & $2.16 * *$ \\
\hline Rel_poor & 0.016 & $2.18 * *$ & -0.033 & -0.59 \\
\hline Rel_rich & -0.016 & $-1.87^{*}$ & 0.038 & 0.71 \\
\hline Living in the East & 0.102 & $18.47^{* * *}$ & -0.934 & $-16.58 * * *$ \\
\hline Employed & -0.013 & $-1.66^{*}$ & 0.044 & 0.77 \\
\hline Unemployed & 0.139 & $12.86 * * *$ & -0.434 & $-4.00 * * *$ \\
\hline Retired & 0.010 & 0.93 & 0.001 & 0.01 \\
\hline Owner & -0.039 & $-7.04 * * *$ & 0.180 & $4.43 * * *$ \\
\hline Saving Acc. & -0.077 & $-12.17 * * *$ & 0.153 & $3.04 * * *$ \\
\hline Constant & -0.128 & $-8.43 * * *$ & -1.947 & $-17.00 * * *$ \\
\hline
\end{tabular}

*stands for statistically different from zero at $10 \%,{ }^{* *}$ at $5 \%, * * *$ at $1 \%$. The high happiness is defined as LifeSatisfaction $>8$, while the low happiness as LifeSatisfaction $<=5$. For variable definitions see Table $1 \mathrm{~A}$ in the Appendix. 


\section{Figures}

Figure 1: Life Satisfaction distribution by education level Low Education
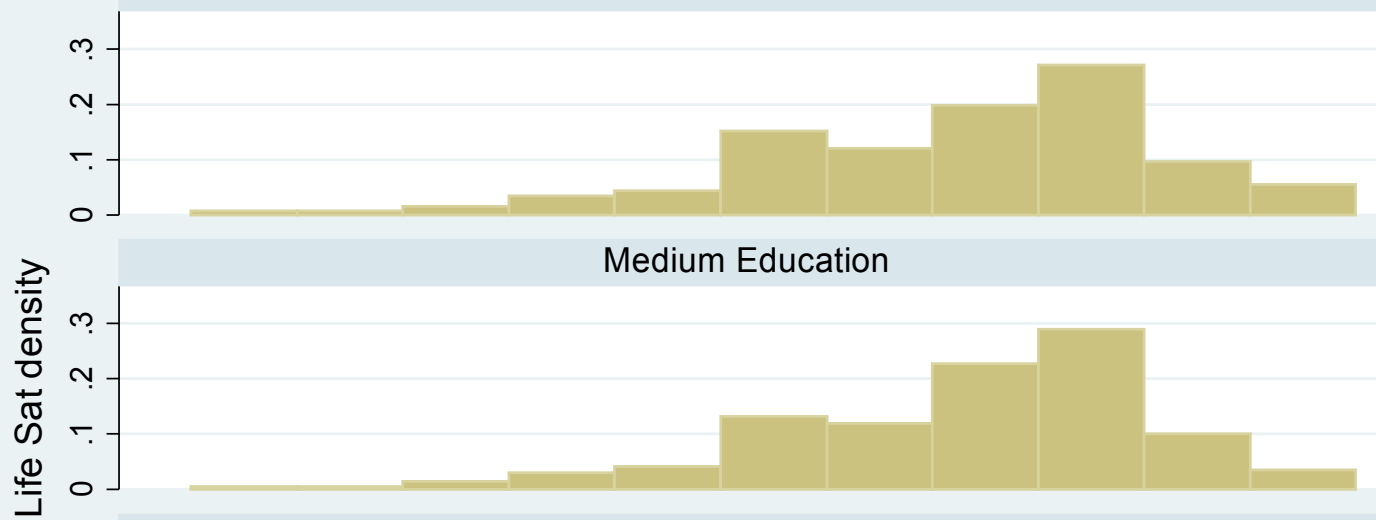

High education

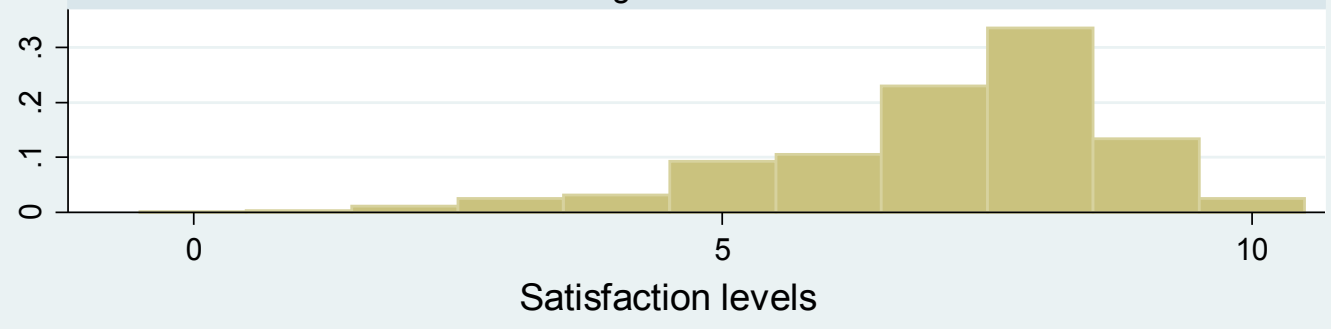

Figure 2: Variance by education levels

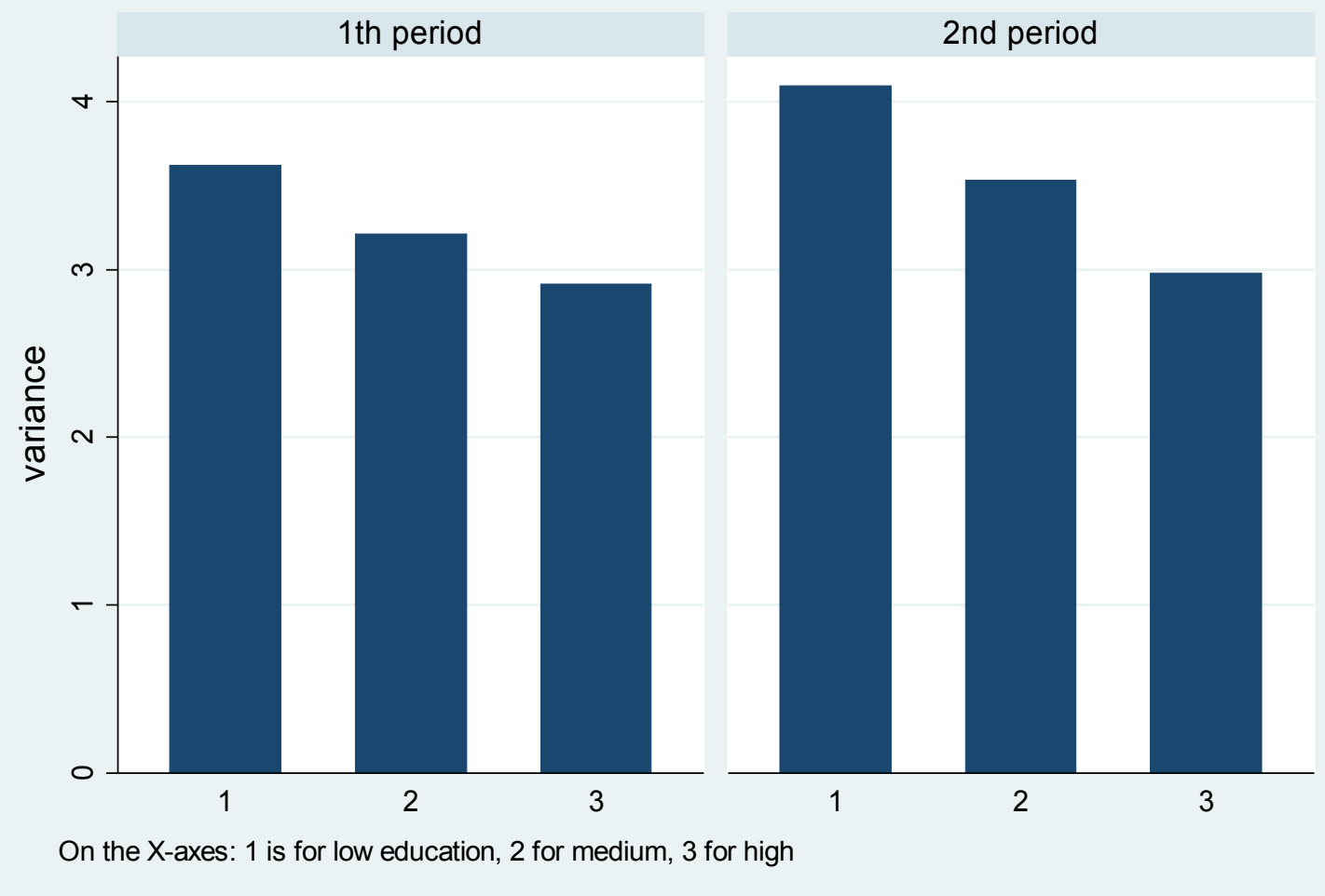


Figure 3: Life Satisfaction distribution by income quintiles

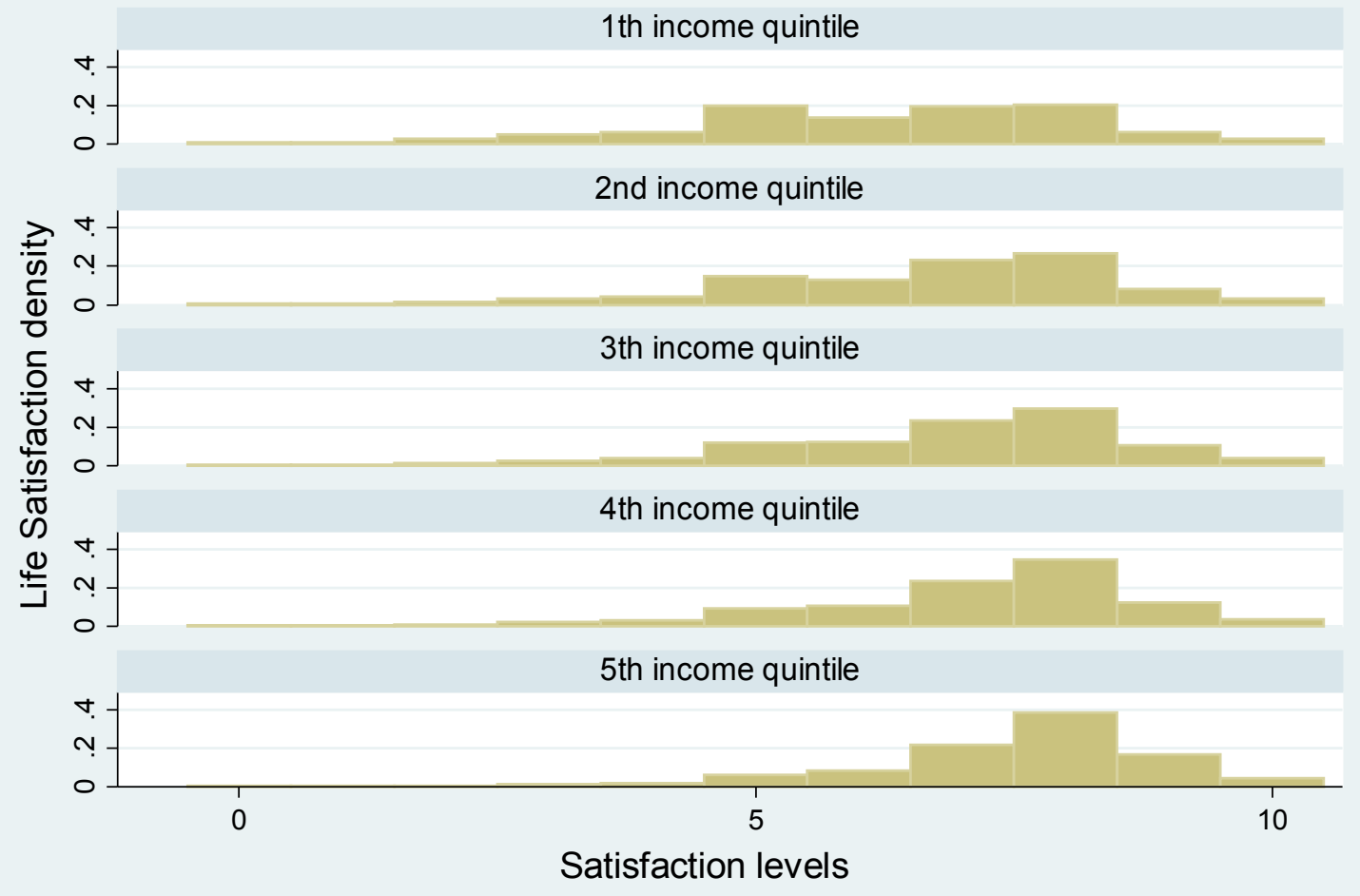

Figure 4: Variance by income quintiles

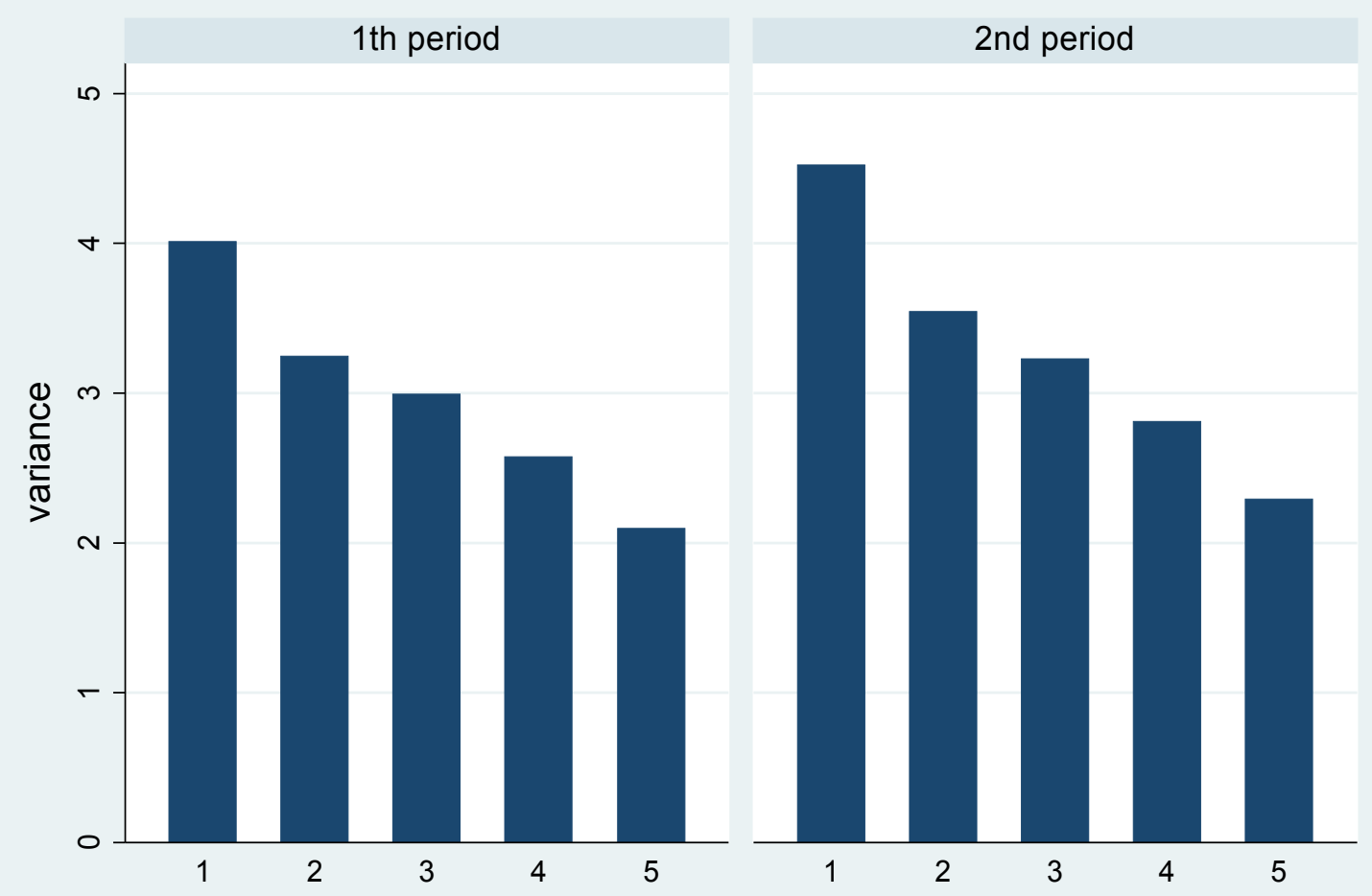


Figure 5: Variance by employment status

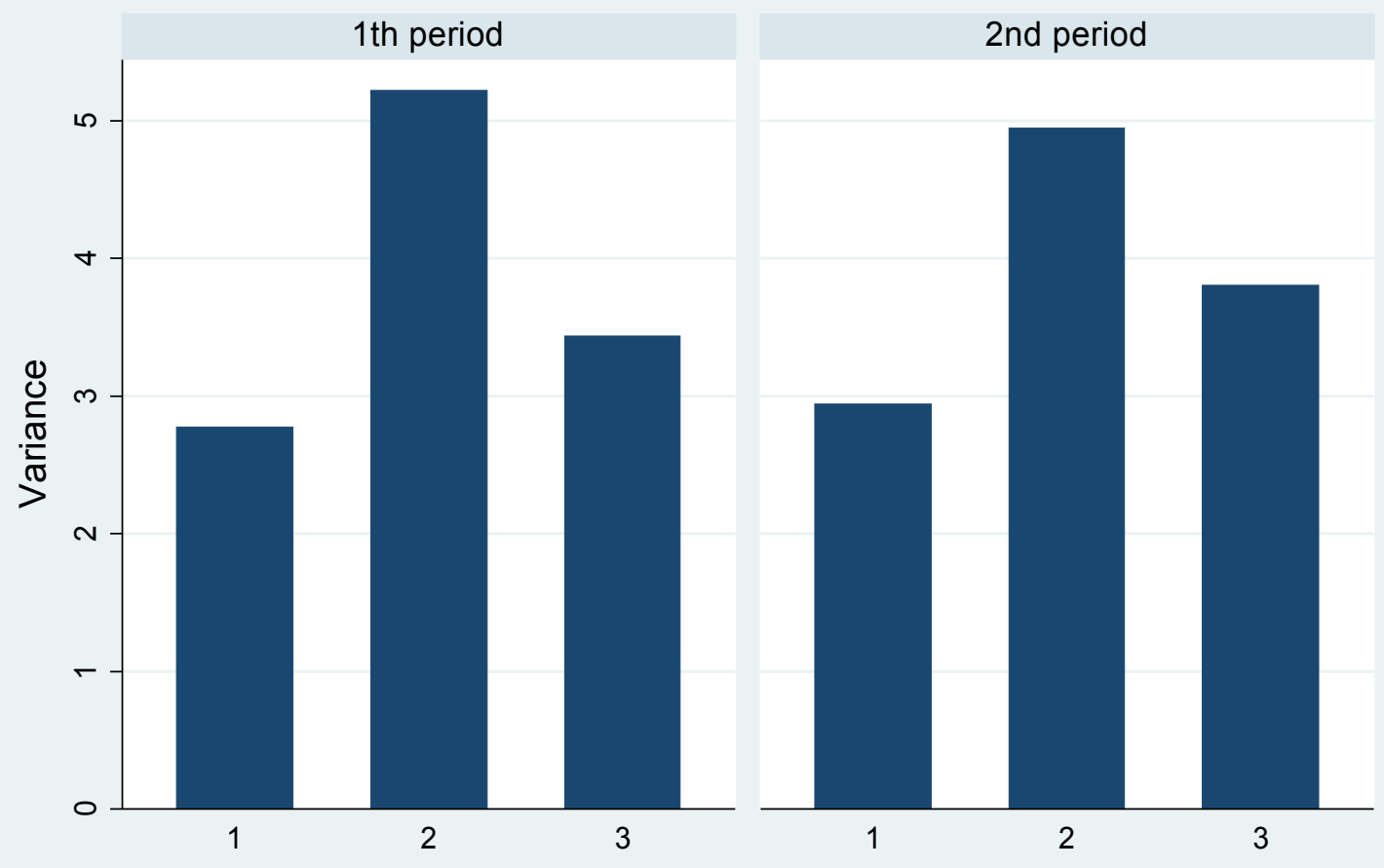

On the X-exes: 1 is for Employed, 2 for Unemployed, 3 for Inactive individuals

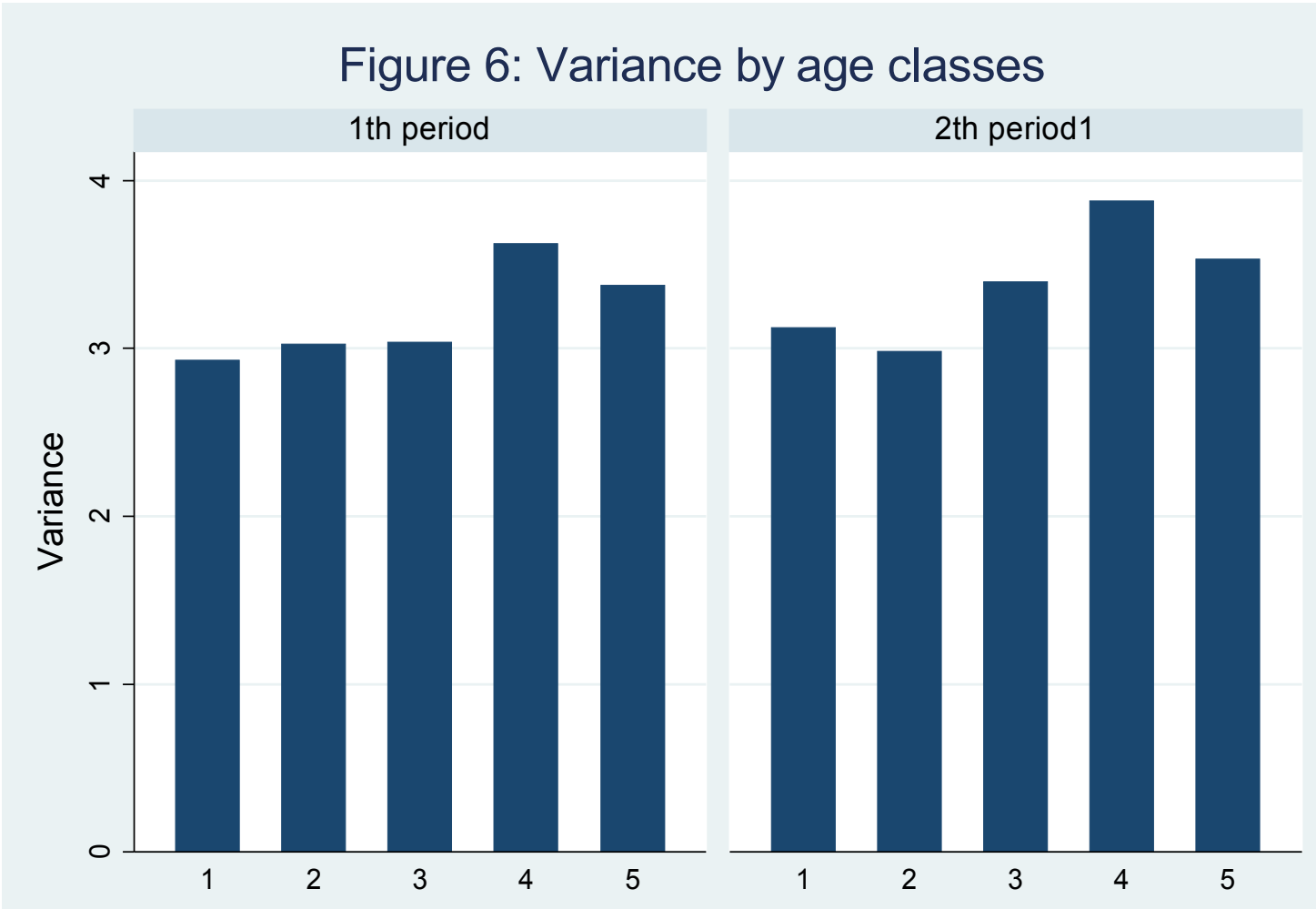

Legenda for age classes: 1 for '18-24', 2 for '25-34', 3 for '35-44', 4 for $45-54$ ', 5 for 55-64' 


\section{Appendix}

\begin{tabular}{|c|c|}
\hline efiniti & \\
\hline Male & Dummy variable equal to one if respondent is male \\
\hline East & Dummy variable equal to one if respondent lives in the East \\
\hline Age 17-24 & Dummy variable equal to one if respondent's age is between 17 and 24 \\
\hline Age 25-34 & Dummy variable equal to one if respondent's age is between 25 and 34 \\
\hline Age 35-44 & Dummy variable equal to one if respondent's age is between 35 and 44 \\
\hline Age $45-54$ & Dummy variable equal to one if respondent's age is between 45 and 54 \\
\hline Age 55-64 & Dummy variable equal to one if respondent's age is between 55 and 64 \\
\hline Low educ & ISCED category $1-2$ \\
\hline Medium educ & ISCED category 3-4 \\
\hline High educ & ISCED category 5-6 \\
\hline Inc_1 & $\begin{array}{l}\text { Dummy variable equal to one if the respondent's income is in the first income } \\
\text { quintile of the pooled sample }(1991,1992,2006,2007)\end{array}$ \\
\hline Inc_2 & $\begin{array}{l}\text { Dummy variable equal to one if the respondent's income is in the second } \\
\text { income quintile of the pooled sample }(1991,1992,2006,2007)\end{array}$ \\
\hline Inc_3 & $\begin{array}{l}\text { Dummy variable equal to one if the respondent's income is in the third income } \\
\text { quintile of the pooled sample }(1991,1992,2006,2007)\end{array}$ \\
\hline Inc_4 & $\begin{array}{l}\text { Dummy variable equal to one if the respondent's income is in the fourth } \\
\text { income quintile of the pooled sample }(1991,1992,2006,2007)\end{array}$ \\
\hline Inc_5 & $\begin{array}{l}\text { Dummy variable equal to one if the respondent's income is in the fifth income } \\
\text { quintile of the pooled sample }(1991,1992,2006,2007)\end{array}$ \\
\hline Rel. Poor & Being in the bottom quartile of the relative pooled income distribution \\
\hline Rel. Rich & Being in the top quartile of the relative pooled income distribution \\
\hline Unemployed & Dummy variable taking value of one if the respondent is unemployed \\
\hline Employed & Dummy variable taking value of one if the respondent is employed \\
\hline Disabled & Dummy variable equal to one if respondent is Disable \\
\hline Retired & Dummy variable taking value of one if the respondent is retired \\
\hline Married & Dummy variable taking value of one if the respondent is married \\
\hline No more married & Dummy variable taking value of one if the respondent is separated \\
\hline No child & Dummy variable equal to one if there are no child livign in the household \\
\hline Saving Account & Dummy variable taking value of one if the respondent has a saving account \\
\hline Owner & Dummy variable taking value of one if the respondent is house owner \\
\hline
\end{tabular}

